\title{
The effect of non-uniform compression and flow-field arrangements on membrane electrode assemblies - X-ray computed tomography characterisation and effective parameter determination
}

Nivedita Kulkarni ${ }^{1}$, Matt D. R. Kok ${ }^{1}$ Rhodri Jervis ${ }^{1}$, Francesco lacoviello ${ }^{1}$, Quentin Meyer $^{1,2}$ Paul R. Shearing ${ }^{1}$, Dan J. L. Brett ${ }^{1 *}$

\begin{abstract}
${ }^{1}$ Electrochemical Innovation Lab, Department of Chemical Engineering, UCL, London, UK, WC1E 7JE
${ }^{2}$ Nanoelectrochemistry Group, School of Chemistry, UNSW, Sydney, Australia, 2032

* Author to whom correspondence should be addressed
\end{abstract}

Tel.: $+44(0) 2076793310$

Web: www.ucl.ac.uk/electrochemical-innovation-lab

Email: d.brett@ucl.ac.uk

\begin{abstract}
The performance of the of polymer electrolyte membrane (PEM) fuel cell is governed by a complex interaction of the structure of the membrane electrode assembly (MEA), cell compression, and operating parameters. Adequate cell compression for improved current collection and gas sealing, can structurally deform MEA with adverse consequences. Nonuniform MEA compression exerted by the flow-field design and arrangement induces heterogeneous transport properties. Hence, understanding morphological evolution and effective transport properties as an effect of MEA compression is an important factor for improving fuel cell performance and durability. In this paper, an X-ray computed tomography study of the entire MEA compression is presented, comprising of gas diffusion and microporous layers, catalyst layers, and the electrolyte membrane, subjected to non-uniform compression under two distinct flow-field arrangements. This study presents a comprehensive dataset of the heterogeneous effective properties required for robust computational modelling; including porosity, permeability, tortuosity, and diffusivity, along with the extent of blocking of the flow channel due to cell compression and effect of compression on the structural properties of the membrane.
\end{abstract}

Keywords: Polymer electrolyte membrane fuel cell; Flow-field; Compression; Effective bulk parameters; Gas diffusion layer; Contact area 


\section{Introduction}

Polymer electrolyte membrane fuel cells (PEMFCs) operating on 'green' hydrogen are a promising technology for reducing carbon emissions in a range of sectors, including automotive propulsion. While the technology continues to improve, there are still some challenges with respect to durability, cost and performance. An improved understanding of the processes occurring within operational fuel cells and optimisation of the cell architecture will accelerate large-scale commercialization of PEMFC technology. The way in which the flowfields are designed and the cell is mechanically compressed, plays a large role in determining operation [1-3]. Significant research has focused on flow-field designs to ensure even reactant distribution over the active area of the cell, adequate removal of product water, and effective current collection [4-7]. Macroscopic flow-fields vary in shape, dimension, orientation, and configuration and are referred to as 'primary' flow fields. In addition to primary flow-fields, some systems rely on the reactant flowing laterally through the gas diffusion layer (GDL), taking advantage of the 'secondary' flow-field, specifically the narrow gap between the GDL and the sealing gasket [8-11].

Cells are typically compressed by $30-50 \%$ to ensure adequate sealing and electrical contact between various components [12,13]. The cell compression not only affects the fuel cell performance, but also the structural and morphological properties of the membrane electrode assembly (MEA), which is composed of a thin electrolyte membrane (typically Nafion), catalyst layer, microporous layer and the fibrous gas diffusion layer (GDL) $[14,15]$. Lu et al. highlighted that flow-field arrangements can affect the structural stresses in the MEA, potentially leading to anisotropic deformation of the membrane [16]. This deformation may induce cracks in the catalyst and microporous layer which will affect the performance and durability of the fuel cell $[17,18]$.

Atkinson et al. showed a nonlinear relationship between the GDL compression and PEMFC performance [19]. Nitta et al. highlighted the nonlinear effect of compression on the electrical contact resistance [20], while, similarly, Ge et al. showed that compression has a significant effect on performance at higher current density, where mass transport becomes critical [21]. Mass transport in the fuel cell, specifically reactant diffusion and liquid water transport through the capillaries, is governed by the materials used in the key components of the MEA and their morphology (e.g., porosity, tortuosity, pore size, and level of deformation). In order to fully understand and optimise the assembly of these components, specifically under compression, it is important to effectively determine these parameters and quantify their effect on cell performance. Zenyuk et al. used X-ray computed tomography (CT) to evaluate multiple 
commercial GDLs under uniform compression; showing decreasing porosity and pore sizes [22]. Tötzke et al. expanded the study by examining the differences between uniformly and non-uniformly compressed GDLs [23]. Non-uniform compressions come from the design of the flow fields, often composed of discrete channel and land zones. Compression by these corrugations leads to constriction of the GDL under the lands and potential protrusion of the carbon fibres into the active channels. This phenomenon, referred to as 'tenting', can result in partial blocking of the primary flow-fields [12].

A study by Kulkarni et al. investigated the effect of uniform GDL compression between two flat plates on lateral deformation in the GDL. Lateral deformation results in the partial blocking of the secondary flow fields as fibers re-align themselves under compression, filling in available void space [24].

A study by James et al. investigated the GDL microstructure under non-uniform compression and found that the microstructural parameters differed based on the region of compression. They also found that these parameters diverged from the values predicted by well-established empirical correlations, [25] emphasising the use of X-ray CT to obtain adequate values for numerical modelling.

X-ray CT is a non-destructive 3D microscopy tool, capable of providing information about the internal structure of the material. At a sufficient resolution, X-ray CT can show the interfaces between the different layers of the MEA and fully resolve the carbon fibres of the GDL, typically 5-10 $\mu \mathrm{m}$ in diameter [17,22,25-30]. Additionally, this technique has been used for studying crack formation in the catalyst layer as well as the membrane degradation mechanisms, such as membrane pinning [31-36].

X-ray CT, used in conjunction with computational modelling, has expanded the understanding of crucial processes taking place inside fuel cells [28,37-43]. The technique has been particularly useful for examining the effect of compression on PEMFCs, but the majority of studies have focused on the GDL under even compression [22,25,29,31,44], and ignore the effect of compression on other layers of the MEA that play a critical role in the fuel cell performance. Therefore, this study considers the entire MEA under non-uniform compression exerted by multiple flow-field arrangements. This work aims to provide a comprehensive dataset of structural and morphological properties of the entire MEA and derive effective parameter values that can be used as inputs to computational models of PEMFC performance. Importantly, the study examines not only 'symmetrical' compression, where the land and channel on both sides of the MEA are perfectly aligned, but also 'asymmetrical' compression 
where a flow-field channel is only present on one side, as is the case in many commercial fuel cell designs. In these designs, hydrogen supply to the anode occurs laterally through the GDL, without a macroscopic flow-field and may rely on a secondary (peripheral) flow-field $[8,45,46]$.

\section{Experimental}

In this work, two commonly used flow-field arrangements were compared, namely symmetrical and asymmetrical flow-fields (Figure $1(a$ and $b)$ ). The symmetrical flow-field is comprised of parallel flow channels on either side of the MEA [47-49], whereas asymmetrical flow-field arrangements have a flow channel on one side of the MEA with a flat plate on the other side $[46,50]$.

\subsection{Materials}

The MEA comprises a Nafion NRE-212 membrane electrolyte (Dupont, USA) and an ELE0201 (Johnson Matthey, UK) gas diffusion electrode (gas diffusion and a microporous layer coated with Pt catalyst layer, $0.4 \mathrm{mg} \mathrm{Pt} \mathrm{cm}{ }^{-2}$ ). The MEA was prepared as per the method discussed by Meyer et al. [51]. The cylindrical MEA samples were cut using a $2 \mathrm{~mm}$ diameter biopsy punch. The sample was mounted on a $3 \mathrm{~mm}$ diameter aluminium piston encapsulated in a Kapton tube. The assembly was then loaded into the compression rig. The pistons had a 1 $\mathrm{mm} \times 1 \mathrm{~mm}$ slot that represents the primary flow-field and a $0.5 \mathrm{~mm}$ gap between the cylindrical MEA sample and the Kapton tube which represents the secondary flow-field.

\subsection{Compression rig}

The in-situ compression rig (MICROTEST 5 kN, Deben, UK) (Figure 1 (c)) offers compression by displacement through movement of the bottom piston towards the fixed upper plate. In this study, four different compressions were imposed on the entire MEA ranging from $0 \%$ (no compression) to $60 \%$ compression, in steps of $20 \%$. Separate experiments were carried out for each flow-field arrangement, using freshly prepared MEA samples. 


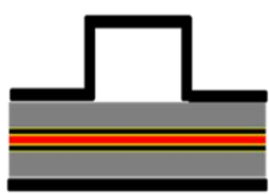

(a) Asymmetrical flow-field

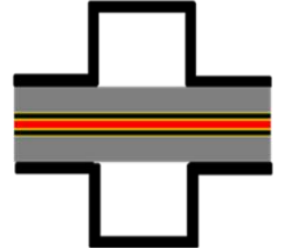

(b) Symmetrical flow-field

\section{Image acquisition}

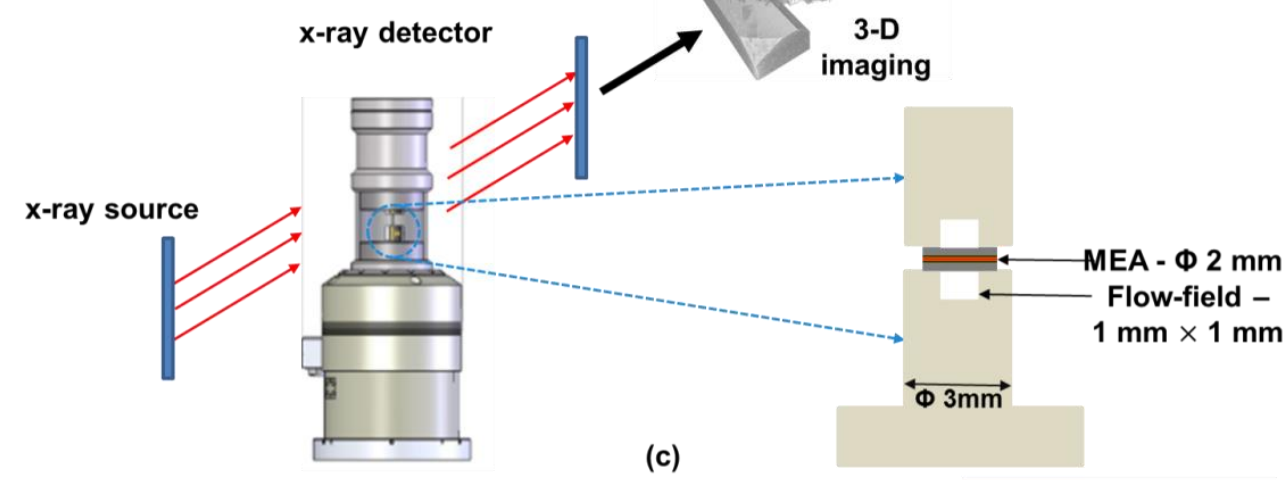

\section{Image processing}

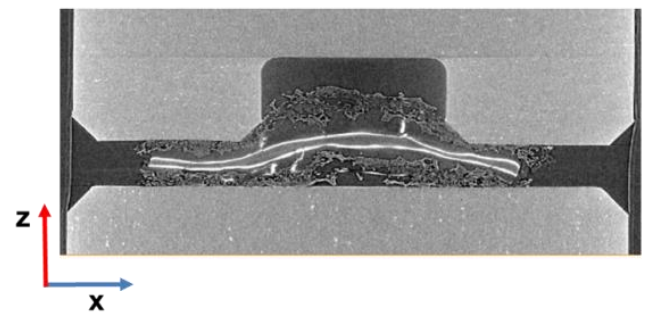

(e)

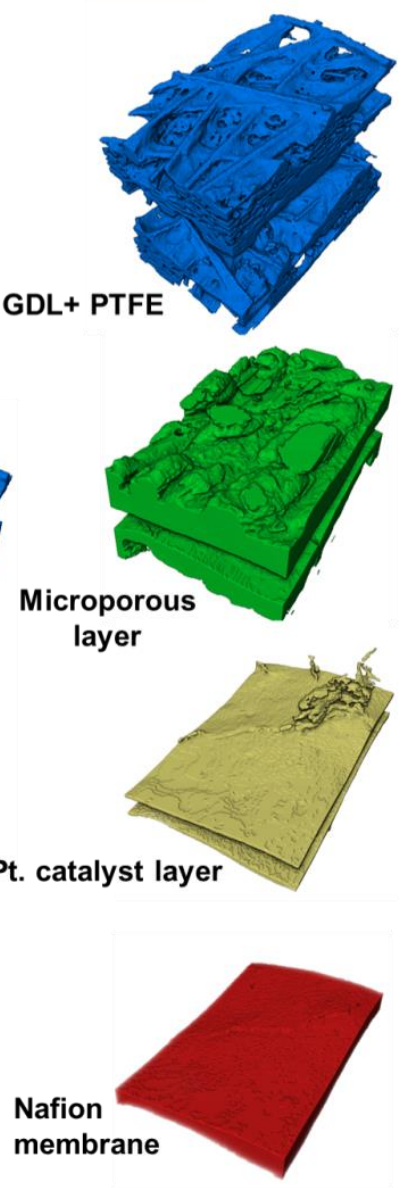

(f) 
Figure 1 Image acquisition (a) imaging set-up with the compression stage; (b) asymmetrical flow-field, and (c) symmetrical flowfield arrangement. And Image processing, visualisation and segmentation (d) 3-D rendering of the reconstructed greyscale data for $60 \%$ compression in the asymmetrical arrangement; (e) greyscale ortho-slice showing an $x z$-plane; and (f) volume rendering of the segmented data with an exploded view of each separate layer in the MEA. The colour legend used for the segmented images is common throughout the paper.

\subsection{Micro-structural characterisation}

\subsubsection{X-ray computed tomography (X-ray CT)}

X-ray tomographs of the sample were obtained using a laboratory-based X-ray CT system, ZEISS Xradia 520 Versa (Carl Zeiss). A source voltage of $80 \mathrm{kV}$ was used to capture 1801 projections with an exposure time of $40 \mathrm{~s}$, through a sample rotation of $360^{\circ}$. A coupled $4 \times$ optic resulted in a field-of-view of $3 \mathrm{~mm}$ and a $1.6 \mu \mathrm{m}$ voxel size. Reconstruction of the radiographs into a 3D volume was achieved using a cone-beam filtered back projection algorithm implemented in commercial software Zeiss Reconstructor Scout-and-Scan [51].

\subsubsection{Image post-processing: visualisation and segmentation}

The image segmentation of all reconstructed volumes, as well as the post-processing, was performed using Avizo Fire (Thermo Fisher Scientific). The geometrical calculations, such as partial blocking of the flow-fields and membrane deflection, were calculated using Fiji/lmageJ open-source code. A typical example of a 3D volume rendering and a phase segmentation of the compressed MEA is shown in Figure $1(d-f)$. Each sample image was segmented into five distinct phases; specifically the carbon fibre GDL and PTFE binder phase (blue), the microporous layer (green), the catalyst layer (yellow), and the Nafion membrane (red). The void space forms the fifth phase but is not shown in the 3D rendering for clarity (Figure $1(f)$ ). In this work, the $z$-direction passes through the thickness of the MEA and is the direction in which the compression was applied.

The generic method for image segmentation, i.e. global thresholding, has been documented in previous studies $[27,28,52,53]$. This approach is useful for the initial segmentation of the phases; however, it is not always very accurate where greyscale values of the component overlap. This can be due to either the phases with similar absorption or the artefacts or noise during the scanning. Hence, a conservative bulk threshold was used to segment the majority of the materials and the 'magic wand' tool was used to fine-tune the phases where grey values were similar [26,34]. A systematic approach with a slice-by-slice segmentation was used to ensure the validity of the phase separation throughout the volume.

The size of the pores in the microporous layer varies from nanometre scale to a few microns, which cannot be effectively resolved at this resolution. Hence, the segmented microporous 
phase includes the void space in the microporous layer. Although a robust segmentation approach was implemented, segmentations are sensitive to chosen threshold values and these sensitivities can affect the effective bulk parameters [54].

The characteristic properties of the compressed MEA are non-homogenous and differ between the channel and the land areas. To better understand the smallest volume at which the effective properties are representing that of the sub-domain, a discrete representative elementary volume (REV) analysis has been applied to the GDL under the sub-domains. The details of REV are provided in the supplementary work.

\section{Results and discussion}

In this section, the X-ray CT analysis of the compressed MEA is presented. The influence of non-uniform compression exerted by flow-field arrangements on the morphology of the MEA is evaluated. The qualitative and quantitative analysis generates a database of the effective parameters required for the numerical modelling of PEMFCs. 


\subsection{Material fraction}

The solid phase fraction describes the distribution of an individual phase along the normalised thickness ( Asymmetrical flow-field Symmetrical flow-field

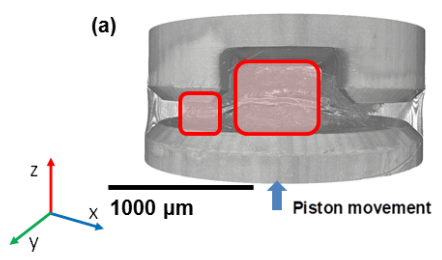

Under the land

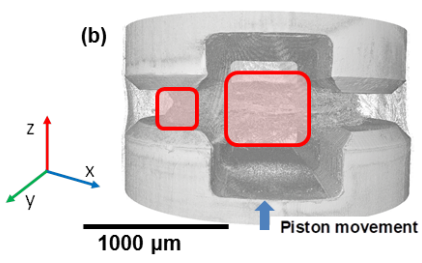

- Gas diffusion layer - Microporous layer - Membrane
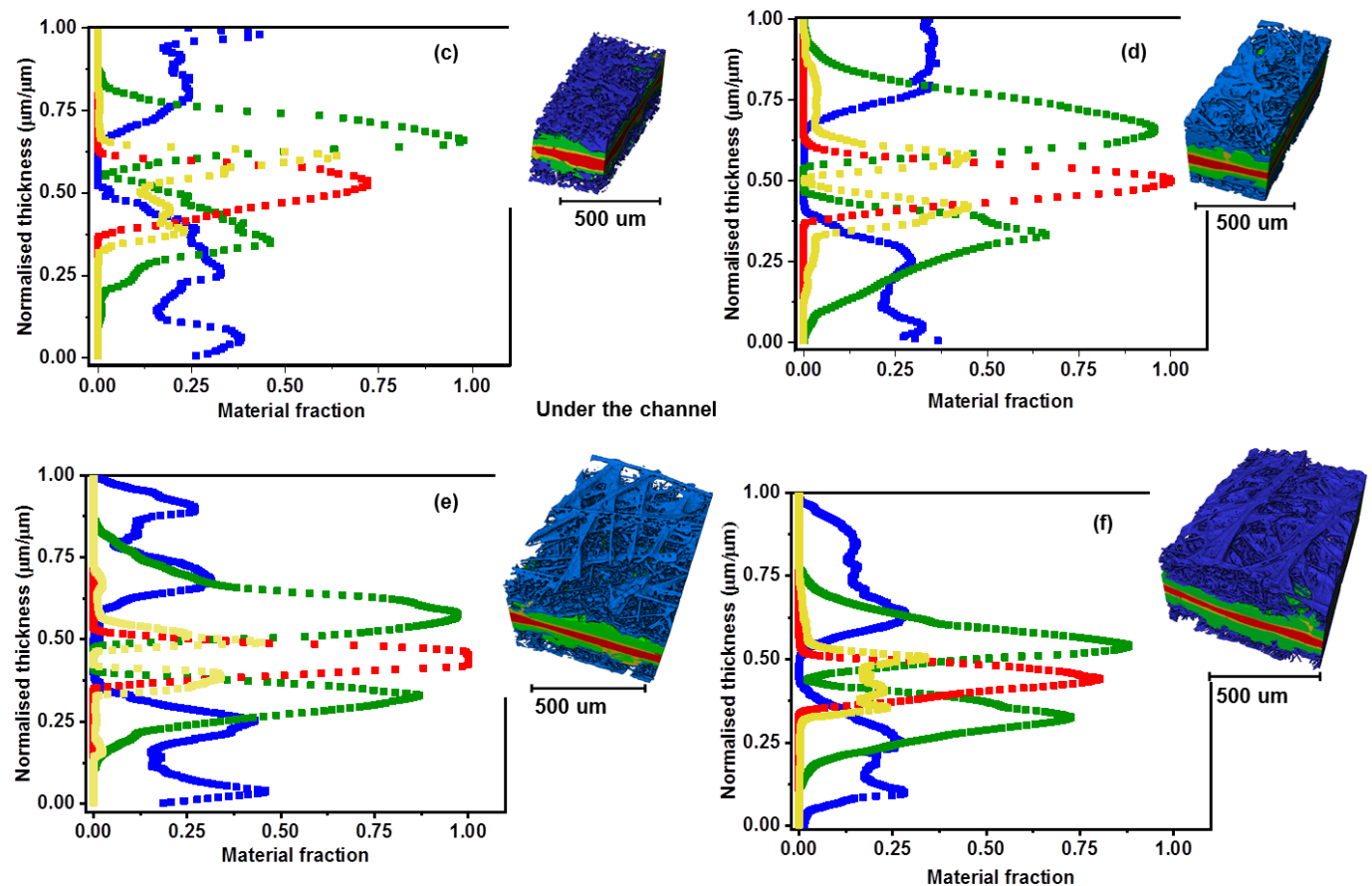

GDL spread - under the channel
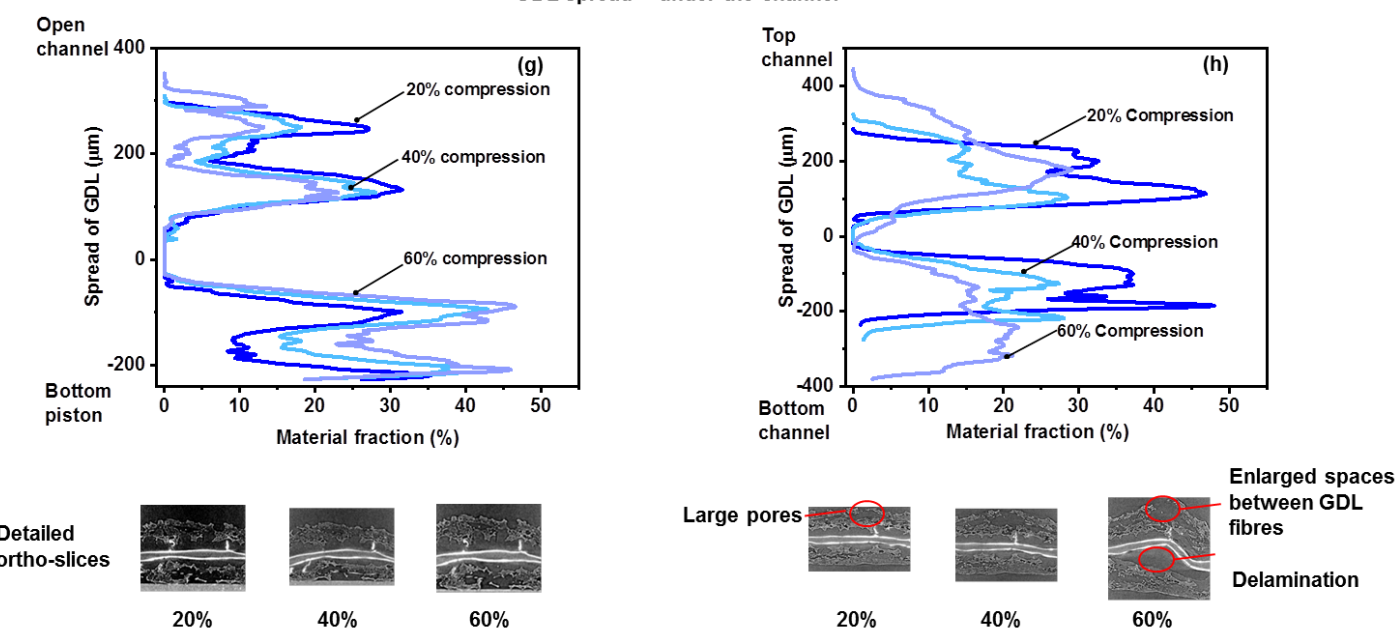

Figure 2). A thickness of zero represents the bottom of the subdomain, while one represents the top. Depending on the location of the subdomain, this could be the interface between the GDL phase and air in the channel or the GDL phase and the piston. 
The catalyst layer and the membrane were relatively unaffected by arrangement and sampling location. A number of phases experience significant overlap. During the manufacturing of the gas-diffusion medium, the catalyst ink is deposited on the microporous layer. The ink penetrates into the microporous layer, leading to phase overlap. This overlap remains relatively unaffected by the compression and arrangements. 
Secondary overlap exists between the microporous layer and carbon fibre GDL. At $40 \%$ compression, irrespective of the arrangement, the entire microporous layer invades $65 \%$ of the GDL phase under the land (

Asymmetrical flow-field

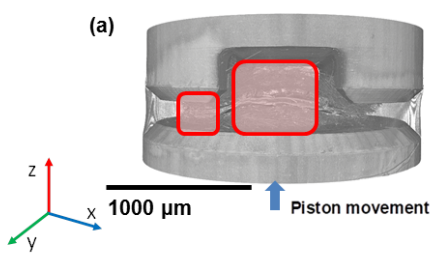

Symmetrical flow-field

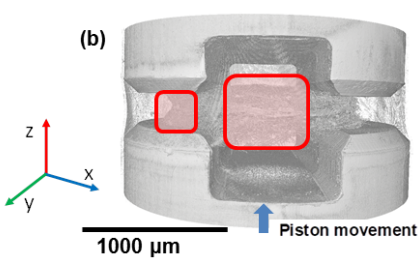

= Pt Catalyst layer

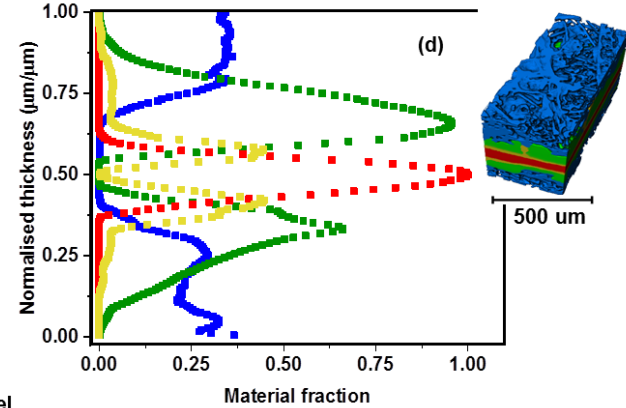

Under the channe

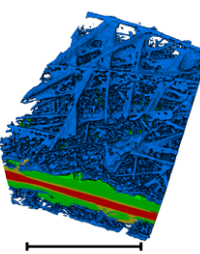

500 um

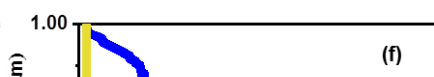

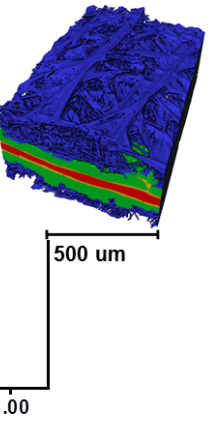

GDL spread - under the channel
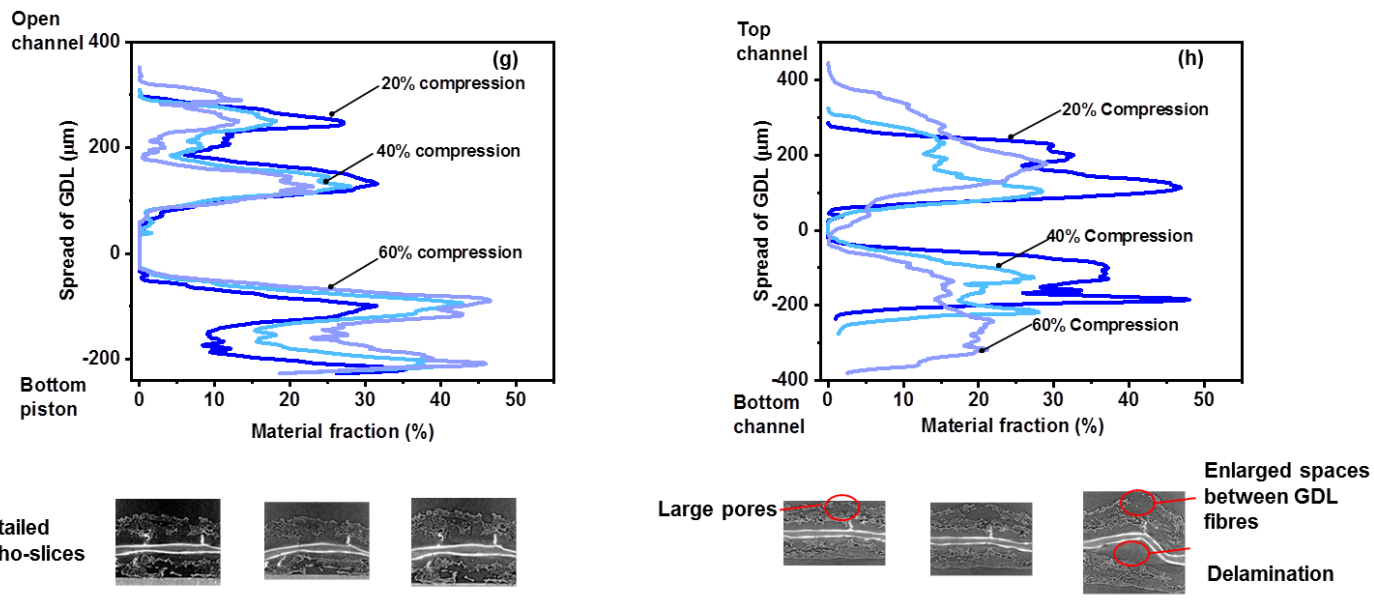

$20 \%$

$40 \%$

$60 \%$ 
Figure 2 (c and d)), and approximately 52\% under the channel ( Asymmetrical flow-field

Symmetrical flow-field
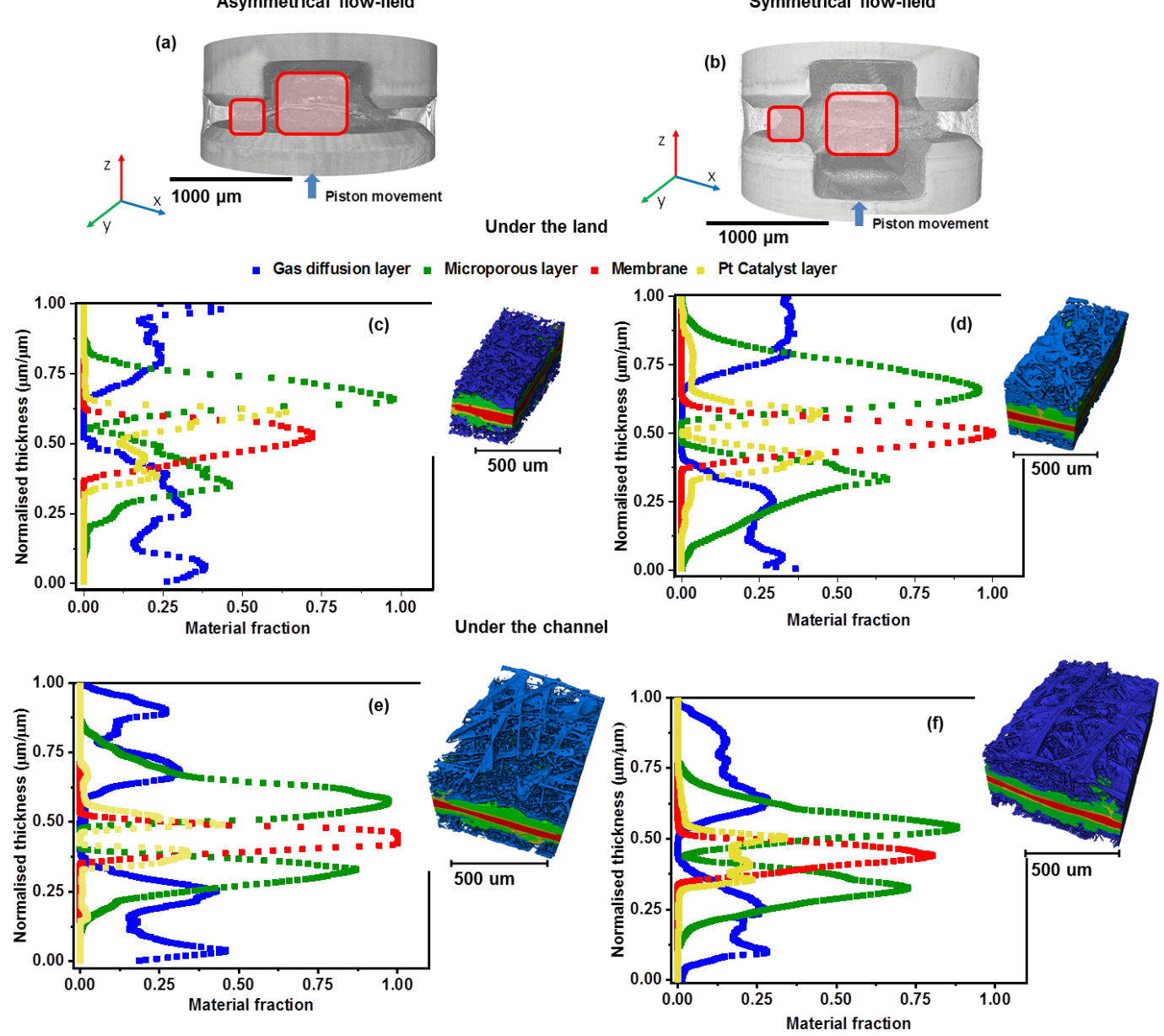

GDL spread - under the channel
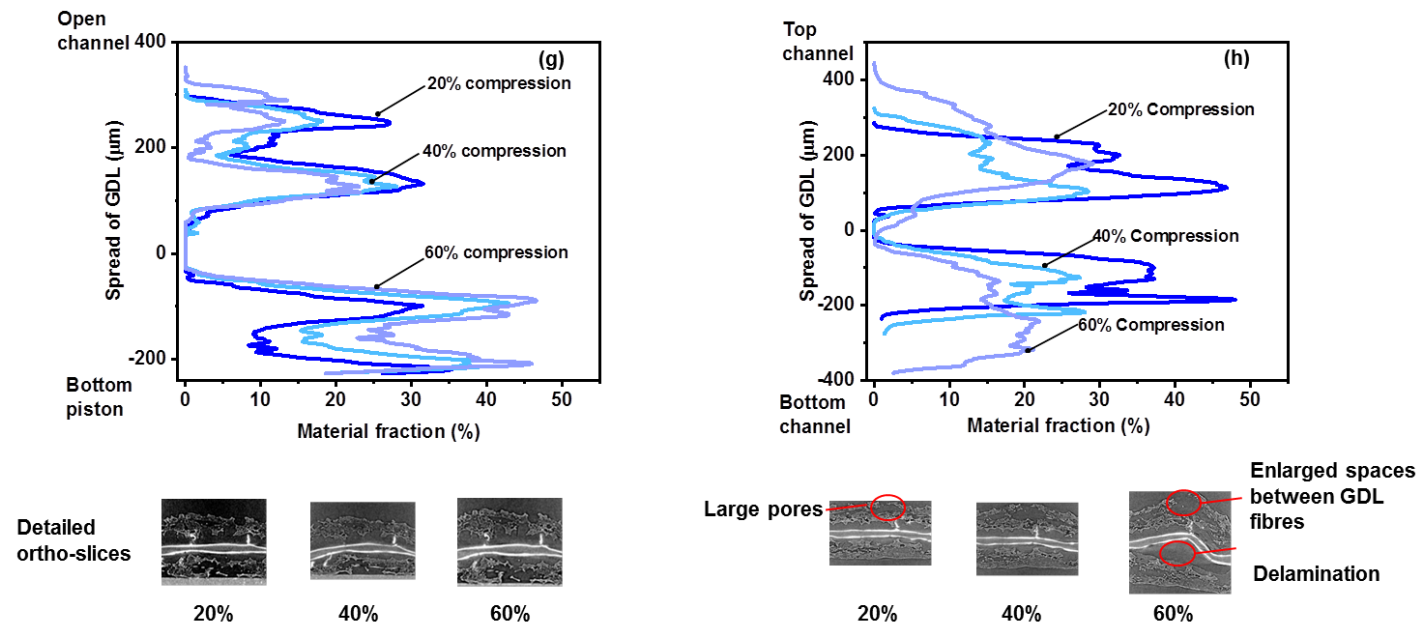

Figure 2 (e and f)). The extent of MPL intrusion into GDL carbon fibres is largely dependent on the material recipe, fabrication process, and the method of MPL deposition onto the carbon fibers. These complex interactions between the GDL and the micro-porous layer have been previously reported by Odaya et al., Atkinson et al. and García-Salaberri et al. for carbon fibre GDLs [19,38,55]. 
Depending on the arrangement, the overlap behaved differently on either side of the membrane. Relatively uniform overlap was observed in the symmetrical arrangement, while in the asymmetrical arrangement, the overlap was $25 \%$ higher in the bottom region of the subdomain. This was due to the restricted space offered by the asymmetric arrangement which prevented expansion of the GDL on the bottom side of the sample.

The GDL thickness distribution forms a characteristic ' $W$ ' shape due to inherent heterogeneities incurred during the fabrication process. Previous 'GDL only' studies on Toray carbon fibre paper as well as fibre-based felt type Freudenberg GDL have seen similar results $[38,56,57]$. Fishman et al. attributed this behaviour to the 'ply molding process' commonly used in GDL fabrication [58], where others have suggested this could be due to the typical agglomeration of the binder and PTFE in the gas diffusion layer [38]. This characteristic is less pronounced under the land, possibly due to the preferential realignment of the GDL fibres under compression.

Figure 2 ( $g$ and $h$ ) shows the change in GDL material fraction with compression for the subdomain under the channel. At lower compression (20\%), the fibres spread relatively evenly on either side of the membrane, independent of arrangements. With the asymmetrical arrangement, the previously explained restricted expansion results in distinct fibre density distributions on either side of the membrane. For the symmetrical arrangement, the GDL expands into the channels with compression in both directions, lowering the solid phase volume on either side of the membrane. The manufacturing heterogeneities in the gas diffusion medium, such as large pores and PTFE loading, may affect the microstructural behaviour of the sample at higher compression by the augmentation of the space between the GDL's fibres near large pores (Figure 2 (h)) [19,22,25,59-61]. The $x z$-ortho-slices in the detailed view gives the pictorial representation of the compressed sub-domain under the channel. 

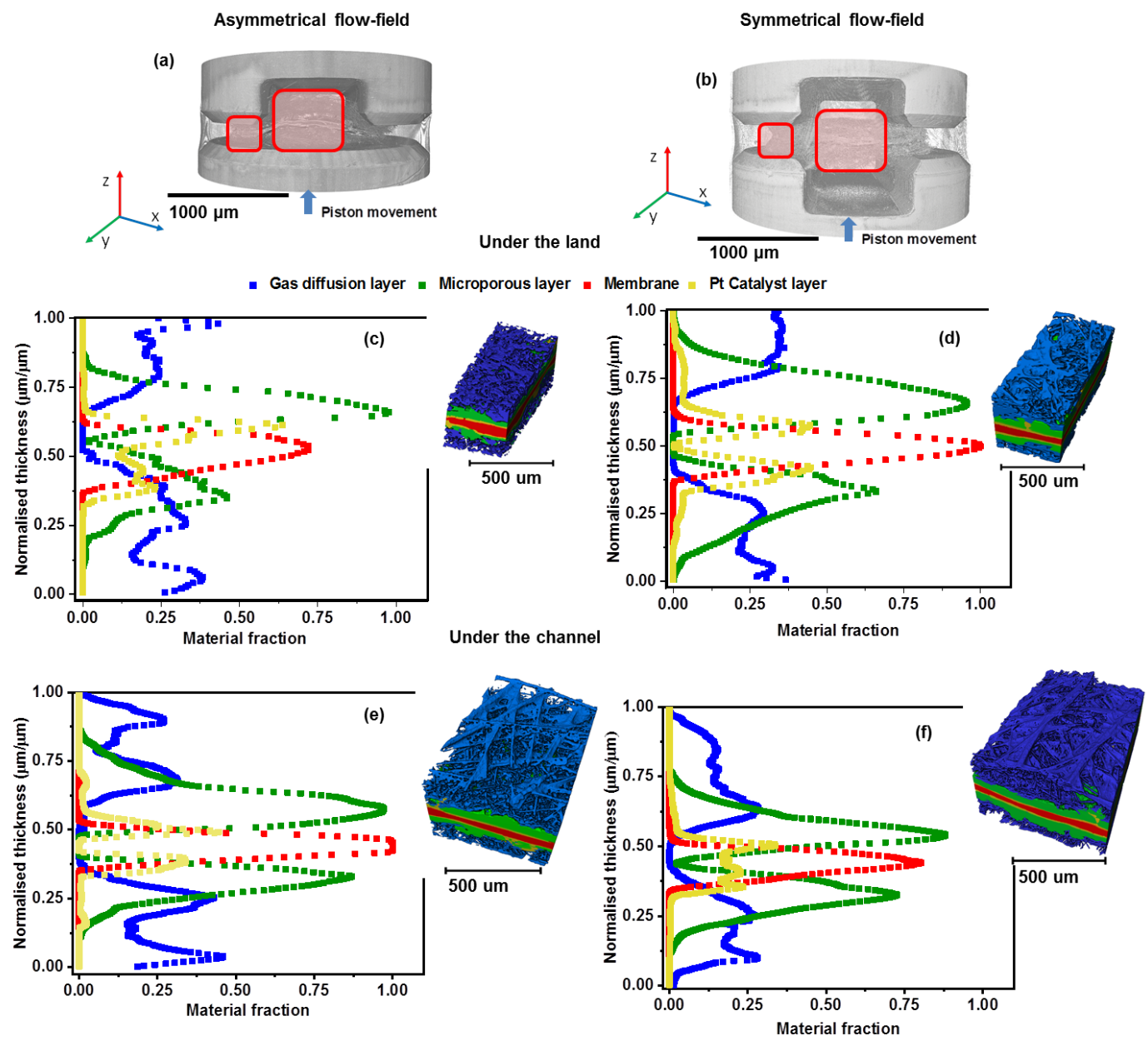

GDL spread - under the channel
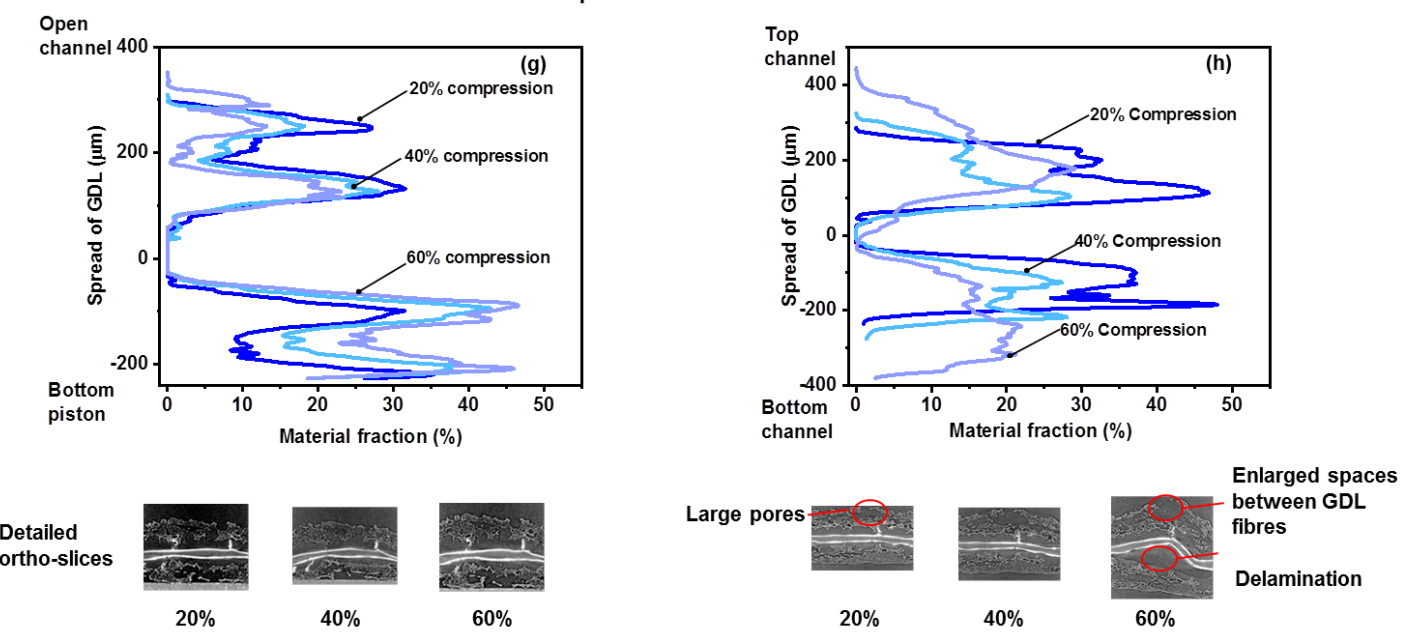

Figure 2 X-ray CT of $40 \%$ compression revels solid-phase material fraction of the individual phases along the normalised thickness (z-direction) (a,b) volume rendering image of asymmetrical and symmetrical arrangement; (b,c) solid-phase material fraction under the land at $40 \%$ compression; (e,f) solid-phase material fraction under the channel; and ( $\mathrm{g}, \mathrm{h})$ change in the solid fraction of the GDL along the thickness under the channel with an increase in compression from $20 \%$ to $60 \%$ at asymmetrical and symmetrical flow-field arrangement respectively. 


\subsection{Partial blocking of the flow-field and the membrane deflection}

X-ray CT ortho-slices shown in Figure 3 ( $a$ and b) illustrate the effect of compression on the vertical and lateral deformation of the GDL. The vertical deformation clearly shows the GDL protruding into the flow channel, potentially blocking the primary flow-field. The lateral deformation of the GDL leads to partial blocking of the secondary flow-field. The extent of the blocking was calculated as the reduction in void volume in the flow-field.

The degree of blocking of the primary flow-field was affected by both the arrangement as well as the degree of compression (Figure 3 (c)). In the asymmetrical case, $45 \%$ of the primary flow-field was blocked, versus $25 \%$ of the total channel space in the symmetrical arrangement (15\% top and $10 \%$ bottom) was blocked. These measurements were made at the typical case of $40 \%$ compression. GDL deformation in the secondary flow-field was largely caused by compression, while the flow-field arrangement did not play a key role (Figure 3(d)). The deformation increased with increasing compression.

Figure 3 ( $a$ and $b$ ) also shows the effect of the compression and the different arrangements on the membrane deformation. To the authors' knowledge, this is the first time that the X-ray CT has been used to quantify the effect of the arrangement on the structural deformation of the membrane under compressive load, in isolation from chemical / hygro-thermal stresses $[16,62,63]$.

Here, membrane deflection refers to non-uniform deformation of the membrane. This phenomenon can be seen clearly on the far right of Figure 3 (b), 60\% compression. The deflection was quantified as the vertical distance between the initial and final mid-plane position of the membrane, correcting for the bottom piston's movement. Membrane deflection was more significant under the asymmetrical arrangement, largely due to restricted compression of the GDL on the opposite surface. Conversely, in the symmetric arrangement, the GDL is able to expand in both directions, leaving minimal membrane deflection until extreme compressions.

Under $60 \%$ compression, the symmetric arrangement experienced misalignment, shifting by $60 \mu \mathrm{m}$. This resulted in the membrane deflection increasing by $30 \%$ as well as the sample delamination, as shown in the highlighted view of Figure 3 (b). Therefore, the membrane deflection is not only subject to the flow-field arrangement and compression, but also to the accuracy of the cell assembly process. 


\section{Asymmetrical flow-field}

Cell compression 20\%
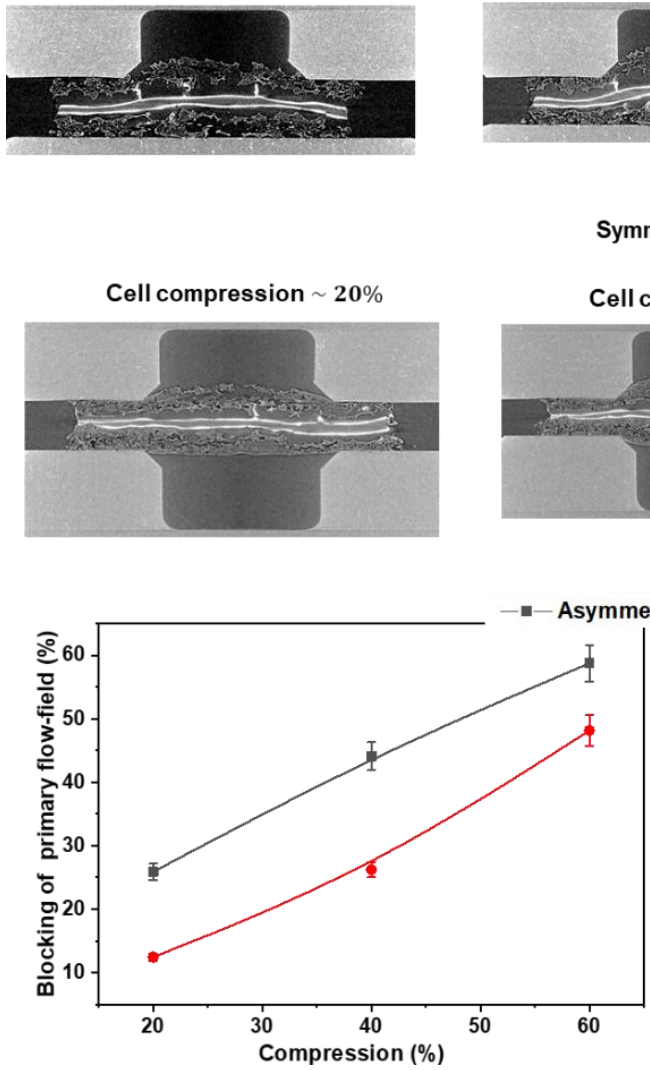

(c)

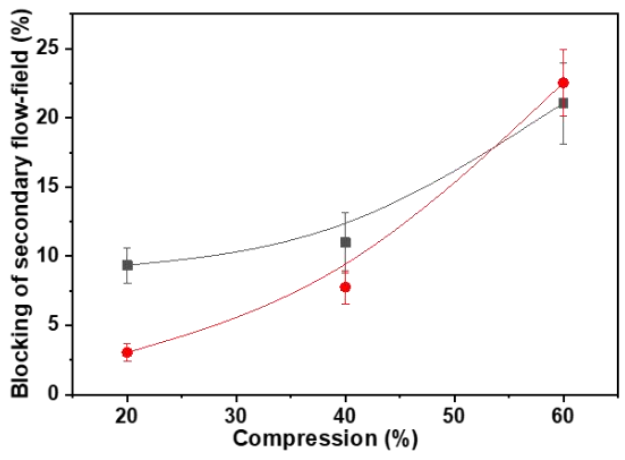

(d)

Cell compression $\sim 60 \%$

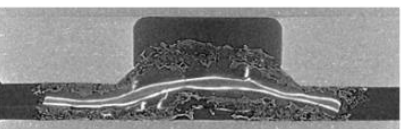

(a)

Symmetrical flow-field

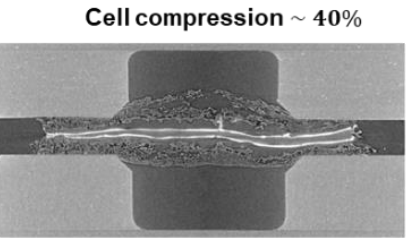

(b)
Cell compression $\sim 60 \%$

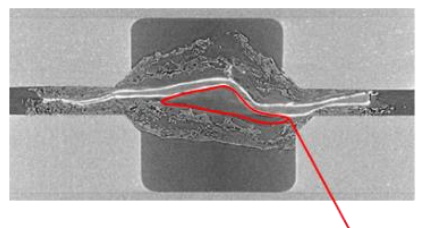

Delamination

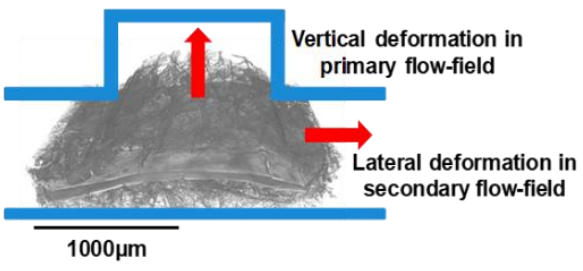

(e)

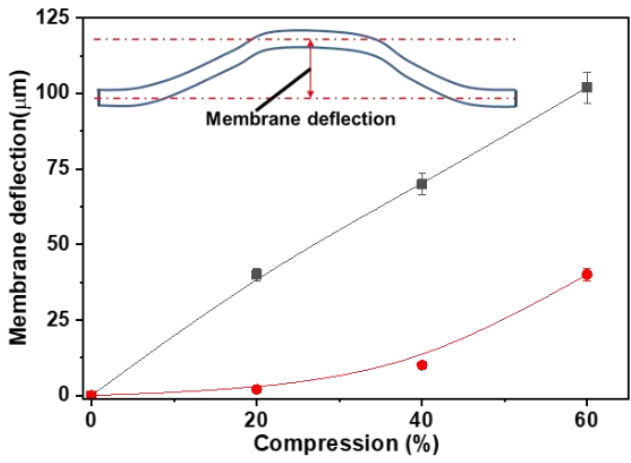

(f)

Figure 3 Partial blocking of the active flow channels, $(a, b)$ ortho-slices showing partial blocking of the flow-field with compression at the asymmetrical flow-field and symmetrical flow-field respectively, (c) extent of the primary flow-field blocking, (d) extent of secondary flow-field blocking, (e) schematic of MEA deformation in vertical and lateral direction, (f) quantification of membrane deflection in $+z$ direction. Membrane deflection schematic shows the location where membrane deflection was measured. Bspline passing through the data points is included as a guide to the eye. Note: At $60 \%$ compression in symmetrical flow-field, the top piston laterally slipped by $60 \mu \mathrm{m}$ inside the compression stage. 


\subsection{Structural thinning of the membrane}

The localised membrane thickness was calculated based on the local thickness method derived from the binary image; defined by the diameter of the largest sphere, that entirely fits in the domain (Figure $4(\mathrm{a})$ ). Regions where a distinct membrane phase could not be segmented, i.e. the thickness was below the material resolution, were not considered and appear white in Figure 4 (a).

Non-uniform compression exerted by the flow-fields results in localised membrane thinning. There was an inherent initial membrane thickness distribution (at zero compression) with a standard deviation of $25.99 \mu \mathrm{m}$ and $25.76 \mu \mathrm{m}$ (average thickness of $45.6 \mu \mathrm{m}$ and $43.04 \mu \mathrm{m}$ ) for the symmetrical and asymmetrical arrangements, respectively. This is a consequence of the MEA fabrication process, where the hot pressing results in varying levels of impregnation of MPL/GDL into the membrane, as identified in previous studies $[51,64]$.

To quantify the change in the membrane thickness, a chord length distribution was employed, as described by Kok et al. [65]. Chords refer to the straight lines drawn at each membrane voxel element, and their length represents the membrane thickness at particular coordinates. The resulting probability density function distribution can be seen in Figure 4 (b) for the asymmetrical and Figure 4 (c) for the symmetrical arrangements. The peak of every distribution represents the expected thickness of the membrane at any given location. Two distinct peaks in the thickness distribution could the collective consequence hot pressing conditions and inherent variation in the membrane thickness [64].

Comparative illustrations of the change in membrane thickness measured under the channel and land region are shown in Figure 4 (d). No noticeable change in the membrane thickness was observed under the channel, irrespective of the arrangements. But significant membrane thinning was detected under the land. At the typical case of $40 \%$ compression, the membrane thinning measured under the land was $6 \%$, regardless of the arrangements. This increased to $7.5 \%$, again regardless of arrangement, at $60 \%$ compression; suggesting that the overall thickness of the membrane under the land reduces with compression. This has not been previously observed in-situ through X-ray CT. 


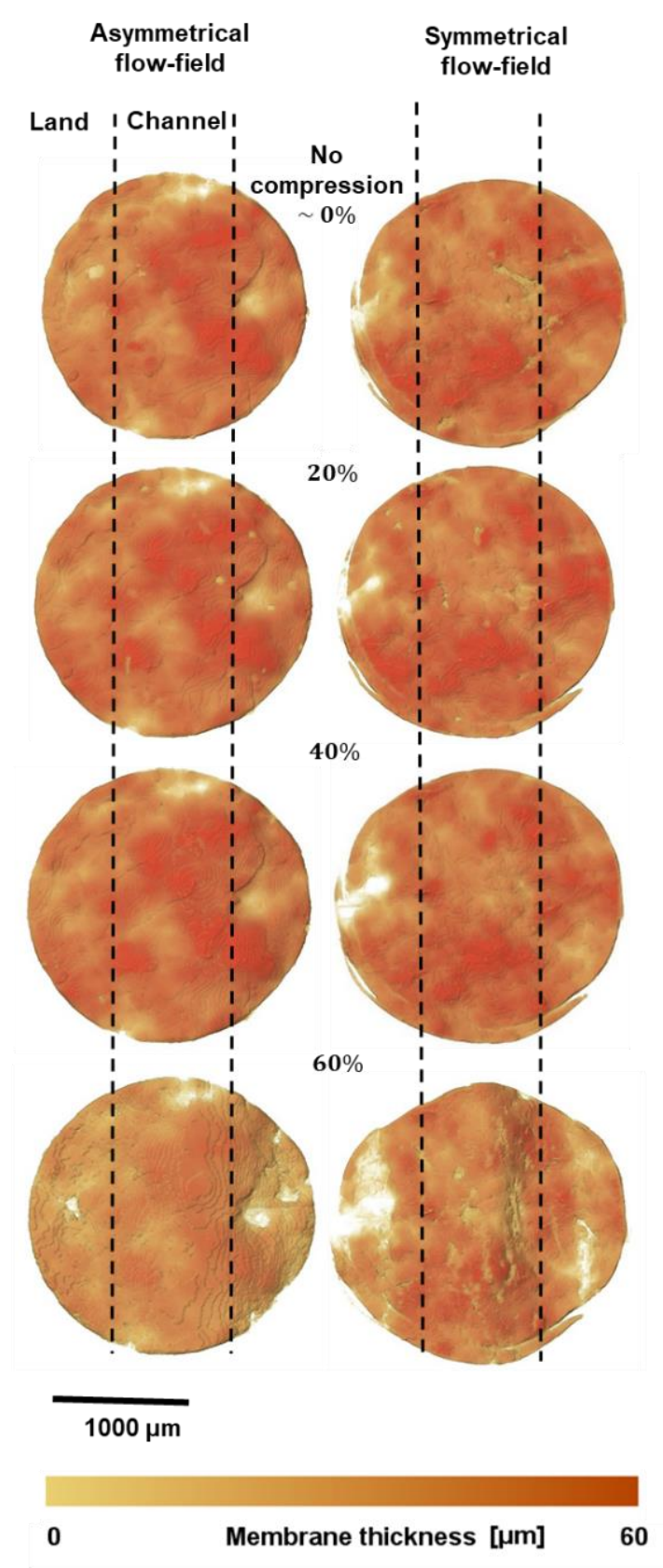

(a)

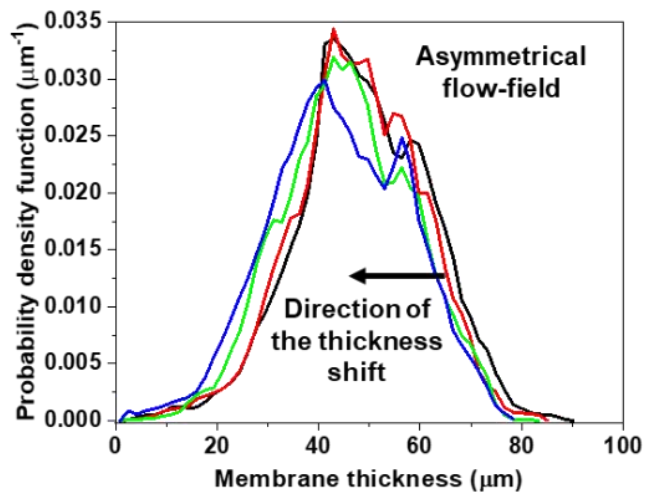

(b)

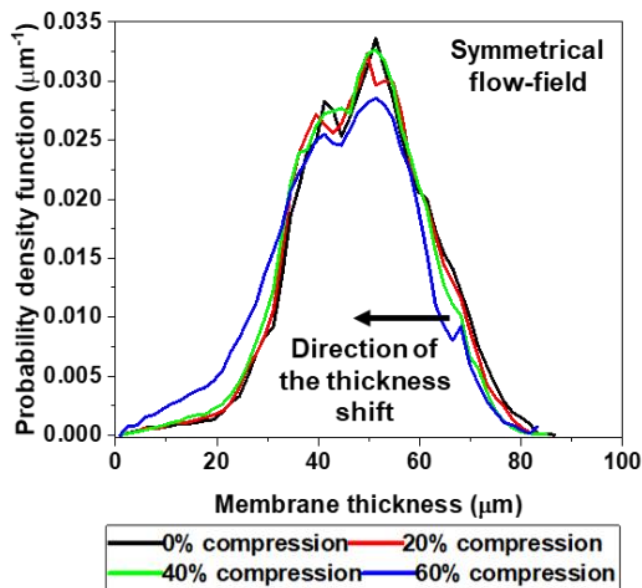

(c)

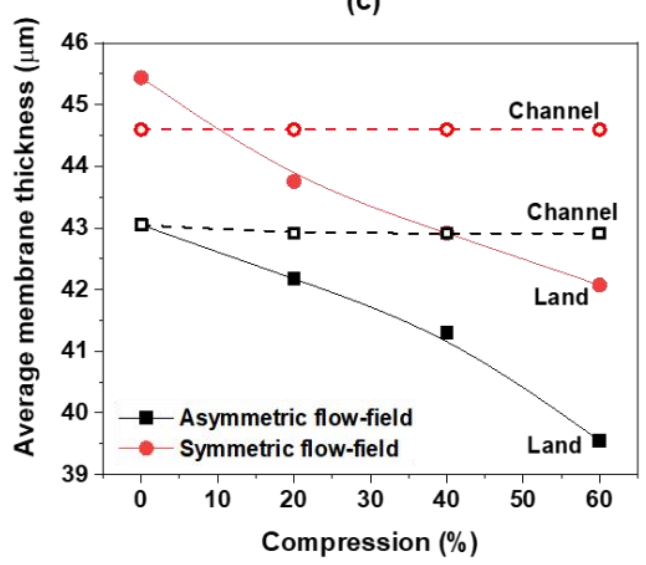

(d)

Figure 4 Thinning of the membrane; (a) thickness map of the membrane as a function of compressive load comparing the two different flow-field arrangements, the perforated black line represents the division between the land and the channel regions;

(b) thickness distribution in the membrane subjected to asymmetrical cell compression; (c) thickness distribution in the membrane subjected to symmetrical cell compression; (d) overall reduction in average membrane thickness measured under the land and under the channel. While red circles represent symmetrical and black squares represents asymmetrical arrangement, the solid point's represents under the land sub-domain and open point's represents under the channel subdomain. B-spline passing through the data points is included as a guide to the eye. 
The thickness of the membrane can significantly affect cell performance. A thinner membrane exhibits lower ohmic losses, while also needing lower cell humidification due to a higher rate of water back-diffusion. At the beginning of a cell's life, these properties will improve cell performance; however, a thinner membrane will also be subjected to higher gas crossover and overall poorer mechanical durability. The rate of electrochemical degradation of the membrane is also a function of its thickness. Thinner membranes are subjected to higher insitu stresses leading to membrane cracking and pinning, further increasing degradation. Similarly, irregularities in the membrane thickness would result in unbalanced behaviour of the aforementioned properties, inducing higher stresses on the mechanical structure of the membrane.

The initial irregularity in the membrane thickness attributes irregular membrane properties. The standard deviation span measured before the cell compression ( $0 \%$ compression) shows the range of error that would be induced in the computational model with uniform membrane thickness. However, the noteworthy point here is, the thinning of the membrane under compression would aggregate the non-uniformity in the transport properties that are required for the robust modelling of PEMFC systems. For example, the gas crossover is inversely proportional to the membrane thickness [66]. Therefore, if the cell is compressed at $40 \%$ under the symmetrical arrangement, $6 \%$ thinning in the membrane thickness under the land would increase the rate of the gas crossover under the land region by $6 \%$. Similar data derived from these results would help to fine-tune the membrane parameters required for continuum modelling.

\subsection{Contact surface area}

The 3D reconstructed volume provides information regarding the effect of the compressive load on the interfacial contact between GDL fibres and the current collector (aluminium piston). The electrical contact resistance was determined by the surface area and the 'quality' of the contact. This is affected by the force exerted between the contacting layers that, along with the nature of the materials, influences the surface contact resistivity. The contact resistance is given by [67-69]

$$
R=\sum_{\text {surfaces }}\left(\sum_{i=1}^{n} \frac{A_{i}}{\rho_{i}}\right)^{-1}
$$

Equation 1

where $R, A$, and $\rho$ are the contact resistance, accumulative contact area i.e. quality of contact and interfacial contact area between fibre and piston, and the resistivity of the contact element, respectively. Increase in compression improves not only the quality of contact between aducent fibres that improves charge transport capacity but also increase the interfacial contact 
area between piston and GDL fibres. The contact resistance is inversely proportional to the accumulative contact area. Therefore, an increase in contact area reduces the contact resistance by same factor.

The $x y$-orthoslices shown in Figure 5 (a) illustrate that the GDL phase density increases with compression when measured under the land. Increased fibre packing density increases interfacial contact between GDL fibres and the piston (current collector) as well as between adjacent GDL fibres. In the present study, the contact area was calculated as the interfacial surface area adjacent to the piston. The contact area was quantified at the region highlighted in red in Figure 5 (b). For a fair comparison between arrangements, the bottom contact area highlighted in green was not considered in the analysis.

For the symmetrical arrangement, the contact area increases by approx. $1.2 \mathrm{~mm}^{2}$ with compression (Figure 5 (c)). Similar observations have been reported in the experimental and modelling studies by Ihonen et al. and Zhou et al. [70,71]. For the asymmetrical arrangement, higher GDL tenting results the fibre reordering under the land as well as under the channel. This increases the interfacial contact area between the channel surface and the GDL fibres concluding in exponential (11\%) increase in the contact at higher compression.

Higher contact area results in subsequent improvement in charge transport and current collection performance at the cost of a reduction in the free-flow area for the reactant. Hence, the combined effect of the compressive load on the change in the interfacial contact area should be considered as a design parameter while designing the flow-field architecture. Moreover; the flow-field arrangements distinctly affects the contact surface area, largely at higher compression. This emphasises the importance of using accurate flow-field arrangements during contact resistance measurement experiments.

Most continuum models predicting PEMFC performance rely on a single value of the effective parameters to analyse the mass transport properties of the diffusive media. GDL fibre alignment, non-uniform compression and flow arrangements result in spatial variations in effective properties. These values are crucial, mainly in two-phase models, where liquid water generation, accumulation, and super-saturation is predicted. In this section, the spatial effective properties that define the reactant transport in the porous domain are discussed. The datasets presented here can be used as the input parameters for the computational modelling of PEMFC performance. 


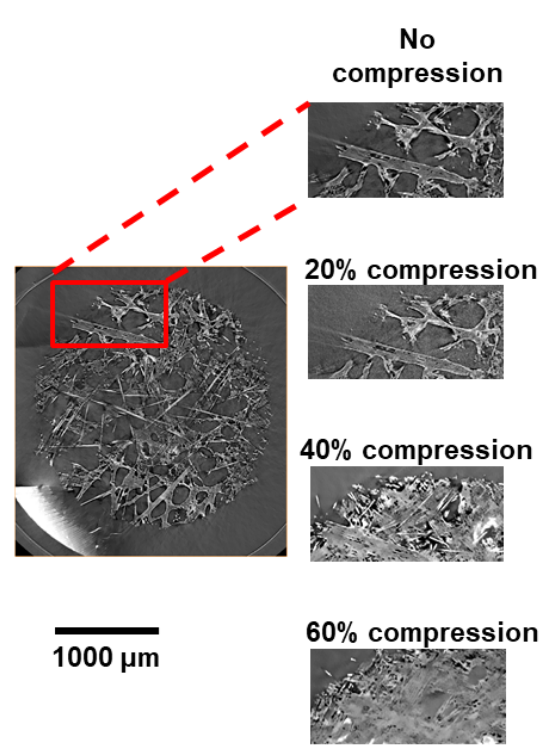

(a)
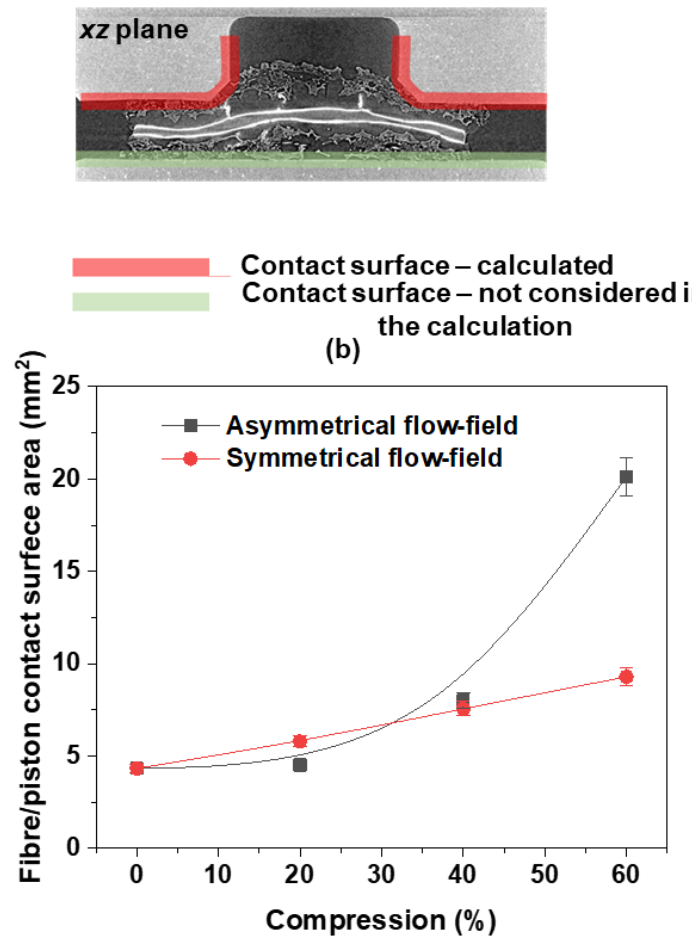

(c)

Figure 5. Effect of compressive load on the contact surface area between the current collector (piston) and GDL fibres; (a) ortho-slice showing the interfacial surface for the asymmetrical flow-field, the area under the red square shows increase in fibre phase density with compression; (b) the contact sub-domain of GDL fibres and the top piston (red) was considered for the quantification of the contact area, and (c) the change in interfacial contact area between GDL fibres and piston with compression. B-spline passing through the data points is included as a guide to the eye.

\subsection{Effective parameters}

\subsubsection{Porosity}

The porosity distribution affects mass transport in the fuel cell, thus the PEMFC performance $[14,15,38,70]$. Both the bulk and spatial porosity distribution should be considered during GDL selection and computational modelling of PEMFCs. Figure 6 shows the effect of the compression and different arrangements on the bulk and spatial porosities of the sample. Bulk porosity is calculated as the volume fraction of empty pores in the domain, whereas spatial porosity is the void fraction of the ortho-slices in particular directions.

Under the land region, fibre packing density increases with compression. This lowers the bulk porosity by $40 \%$ and $50 \%$ (at $40 \%$ compression) for symmetrical and asymmetrical arrangements respectively (Figure $6(\mathrm{a})$ ). In contrast, the GDL tenting under the channel results in a linear increase in bulk porosity with compression. The initial porosity of $45 \%$ increases to $67 \%$ with compression, irrespective of the arrangement (Figure 6 (b)). 


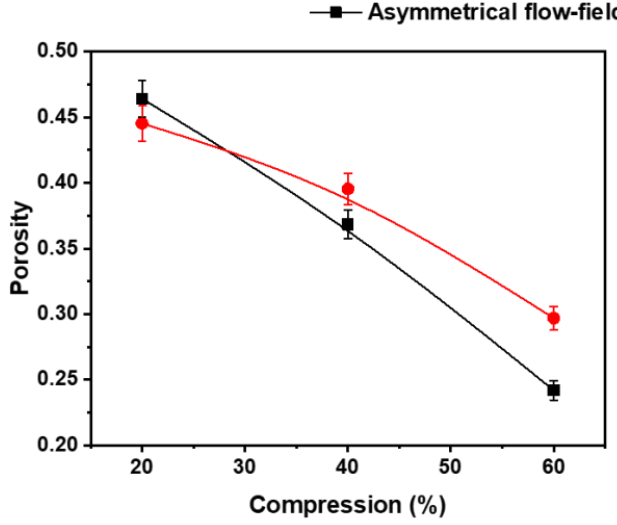

(a)

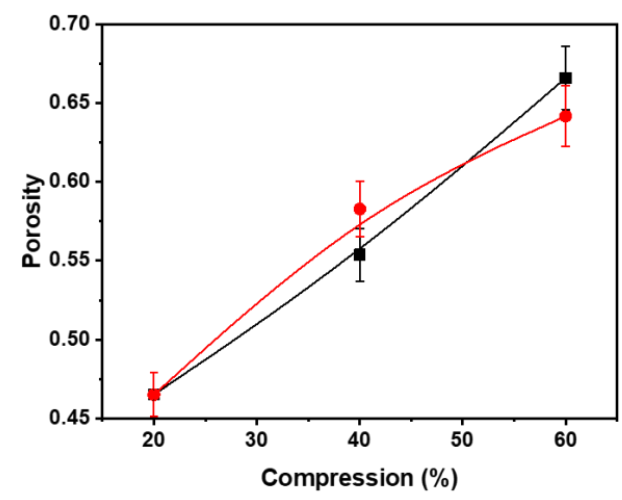

(b)

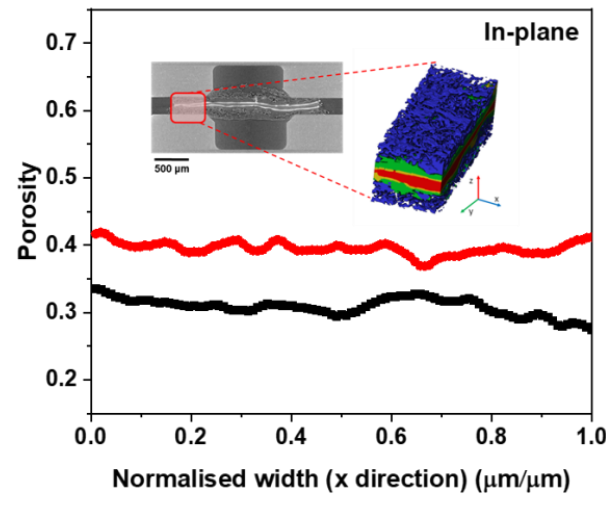

(c)

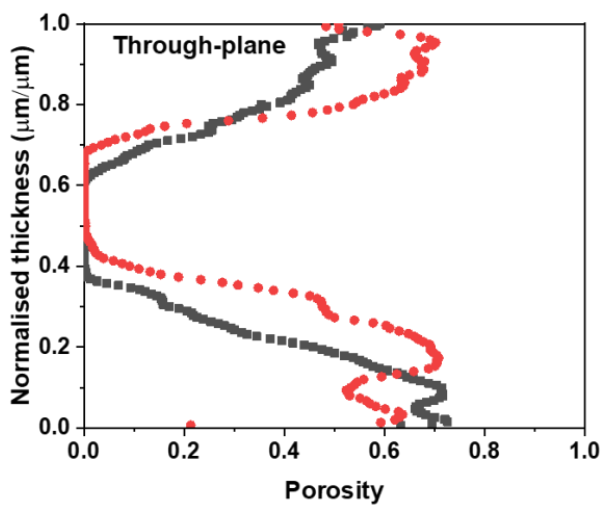

(e)

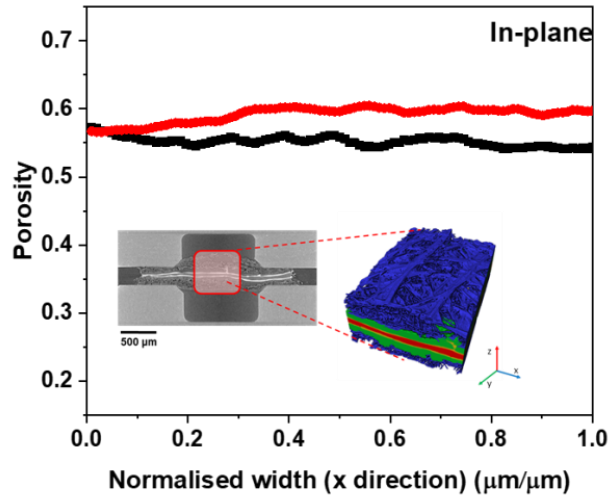

(d)

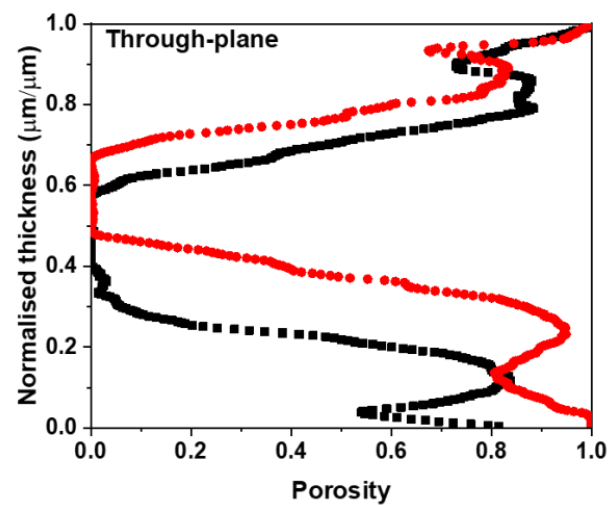

(f)

Figure 6 The effect flow-field arrangement on porosity, symmetrical (red) and asymmetrical (black) flow-fields, (a) bulk porosity under the land; (b) bulk porosity under the channel. Bulk porosity is a ratio of void phase voxel to the total number of voxels. The spline passing through the data points is included as a guide to the eye. Spatial porosity distribution at $40 \%$ compression; (c) in-plane porosity under the land; (d) in-plane porosity under the channel; (e) through-plane porosity under the land; and (f) through-plane porosity under the channel.

Figure 6 (c and d) illustrate in-plane porosity variation at 40\% compression, measured at $y z-$ ortho-slices along the width of the sub-domains. This remained almost constant with a standard deviation of $1.2 \%$ under the channel and $0.98 \%$ under the land, irrespective of the arrangement. The average in-plane porosity matches well with the bulk porosity value. 
The through-plane porosity is a function of the material fraction distribution along the normalised cell thickness (Figure 6 (e and f)). The location of catalyst layers, microporous layers, and the membrane corresponds to the lowest through-plane porosity region. Uniform porosity distribution, irrespective of the arrangement, was observed under the land. However, the through-plane porosity distribution under the channel was affected by the arrangement. The uniform distribution was observed in the symmetrical arrangement, contrasting to the distribution at the asymmetrical arrangement. Comparatively lower through-plane porosity on the bottom-side of the membrane at the asymmetrical arrangement was a function of the restricted GDL expansion on the bottom face.

\subsubsection{Tortuosity factor and diffusivity}

Tortuosity and diffusivity of the GDL was calculated on the binarised dataset of individual samples. Generally speaking, tortuosity is inversely proportional to the porosity; hence, the decrease in bulk porosity with compression increases the tortuous path for the reactant transport and decreases the effective gas diffusivity and vice versa. Therefore, these properties were mainly affected by the location of the sub-domain and were marginally affected by the arrangement (Figure 7).

In this study, the tortuosity factors were calculated using the MATLAB based application 'tauFactor' that uses segmented voxel data for the finite difference simulation. The steadystate scalar diffusion equation was solved with the Dirichlet boundary conditions applied at the opposite faces of the volume. The approach is described by Cooper et al. [72]. The tortuosity factor $(\tau)$ in the specific direction was calculated using the following equation;

$$
\tau=\varepsilon \frac{Q_{\text {controlvolume }}}{Q_{\text {pore network }}}
$$

Equation 2

where $Q_{\text {pore }}$ is the segmented pore network volume, $Q_{\text {control volume }}$ is fully dense control volume with the same outer dimension, and $\varepsilon$ is the volume fraction of the conductive phase. The intrinsic diffusivity (D) was calculated using Fick's second law on the same segmented voxel data used for calculating the tortuosity factor, where the concentration on opposite faces were prescribed using the Dirichlet boundary conditions. The equation used was

$$
\frac{\partial c}{\partial t}=D_{0} \nabla^{2} C
$$

Equation 3

Furthermore, the effective diffusivity $\left(D_{e f f}\right)$ was calculated based on the tortuosity factor using the following expression 


$$
D_{e f f}=D_{0} \frac{\varepsilon}{\tau}
$$

Equation 4

Irrespective of the arrangements, the in-plane tortuosity factor under the land increased by approximately $27 \%$ over the full compression range, whereas under the channel it decreased by approximately $24 \%$ (Figure 7 (a and b)). Similarly, the through-plane tortuosity factor increased by five times under the land and lowered by 2.5 times under the channel over the entire range of compression. (Figure 7 ( $c$ and d)). Again, irrespective of the arrangements, an increase in compressive load decreased the in-plane diffusivity by approx. 34\% under the land and increased it by $44 \%$ under the channel. Similarly, through-plane diffusivity under the land decreased with compression by $90 \%$ and increased under the channel by $44 \%$ irrespective of the arrangement.

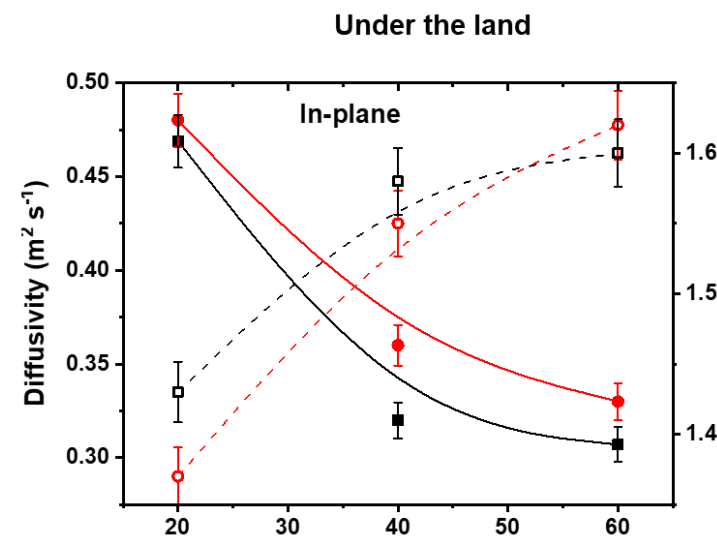

(a)

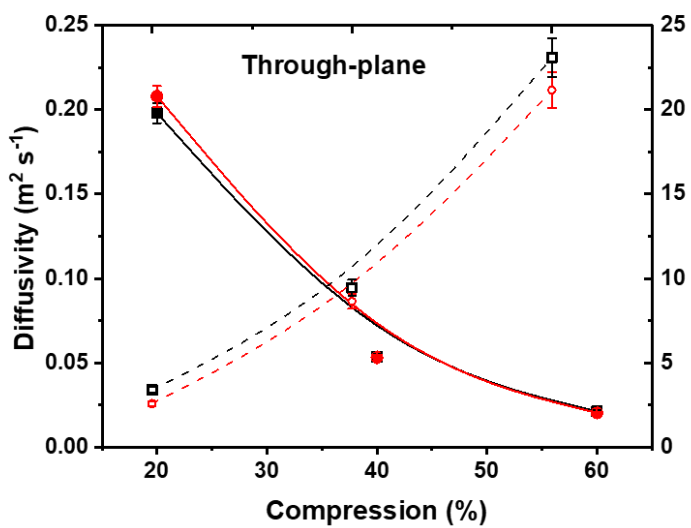

(c)

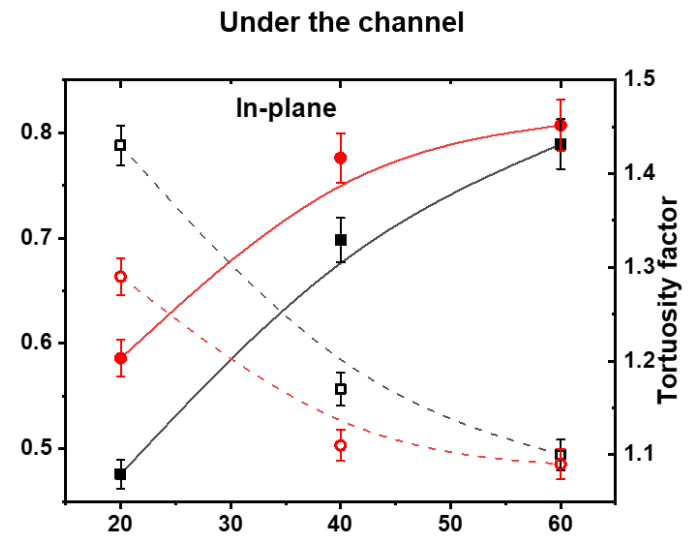

(b)

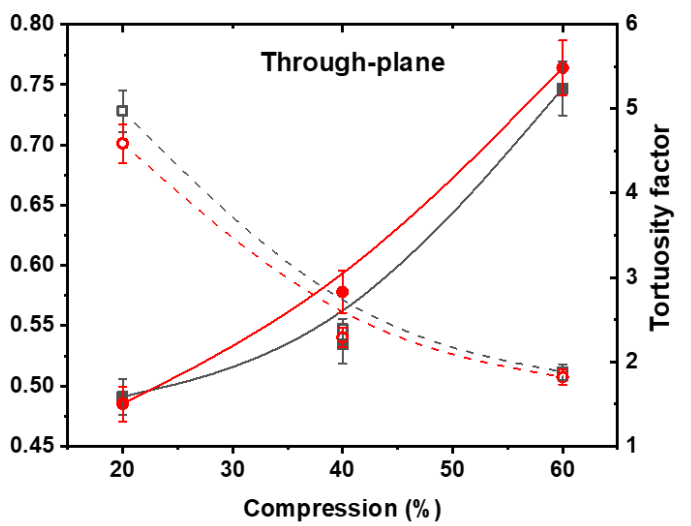

(d)

$$
\begin{aligned}
& \longrightarrow \text { Diffusivity - Asymmetrical flow-field } \longrightarrow \text { Diffusivity - Symmetrical flow-field } \\
& \text { - o- Tortuosity factor - Asymmetrical flow-field - o- Tortuosity factor - Symmetrical flow-field }
\end{aligned}
$$

Figure 7 Directional tortuosity and diffusivity factors calculated on the binarised image of the GDL as a function of compression and flow-field design; (a) in-plane properties under the land; (b) in-plane properties under the channel; (c) through-plane 
properties under the land; and (d) through-plane properties under the channel. Left $y$ - axis represents diffusivity $\left(\mathrm{m}^{2} \mathrm{~s}^{-1}\right)$ and right $y$-axis represents tortuosity factor. B-spline passing through the data points is added as a guide to the eye.

Compression has a major effect on the tortuosity and diffusivity in the through-plane direction, due to the random alignment of the gas diffusion fibres in the $x y$ plane. Fibres realign themselves under compression, thus affecting these properties. The arrangements have minimal impact on these parameters, emphasizing the nonlinear relationship between spatial property distribution, porosity, and fibre alignment.

\subsubsection{Permeability}

The permeability is a function of porosity, often calculated using the Carman-Kozeny equation [73-76]. However, here the flux in each orientation was calculated by 'pressure driven flow simulation' using the Lattice-Boltzmann Method (LBM), and the permeability was calculated by directly applying Darcy's law to the resulting velocity distributions [77]. LB simulations were implemented using Sailfish FD [78] open-source Python package. The simulations utilized the standard Bhatnagar-Gross-Krook (BGK) collision operator with a D3Q13 lattice and were solved for each principle direction of the sub-domain, resulting in three velocity fields for each sub-domain at each compression. The fluid was held at rest initially and the movement was initialized by applying a fixed pressure gradient across the computational volume. The simulation converged when the average proportional deviation, after the iteration, was below $1 \times 10^{-7}$.

The spatial permeability decreases with compression under the land and increases under the channel. Arrangements have a marginal effect on the spatial permeability under-the-land (Figure 8 (a and $\mathrm{c})$ ). For the under the land sub-domain, in-plane permeability reduced by approx. $4 \times 10^{-12} \mathrm{~m}^{2}$, while through-plane permeability by $3 \times 10^{-12} \mathrm{~m}^{2}$ over the compression range for the asymmetrical arrangement.

Arrangements affected the spatial permeability under the channel (Figure 8 (b and d)). The inplane permeability for the asymmetrical arrangement increased over the compression by $30 \times 10^{-12}$ and remained almost constant in the through-plane direction. However, at the extreme symmetrical compression the in-plane permeability increased by $130 \times 10^{-12} \mathrm{~m}^{2}$ and the through-plane permeability by $16 \times 10^{-12} \mathrm{~m}^{2}$. The sudden increase in symmetrical permeabilities at extreme compression was due to the augmentation of the space between GDL fibres near large pores and the delamination observed. 

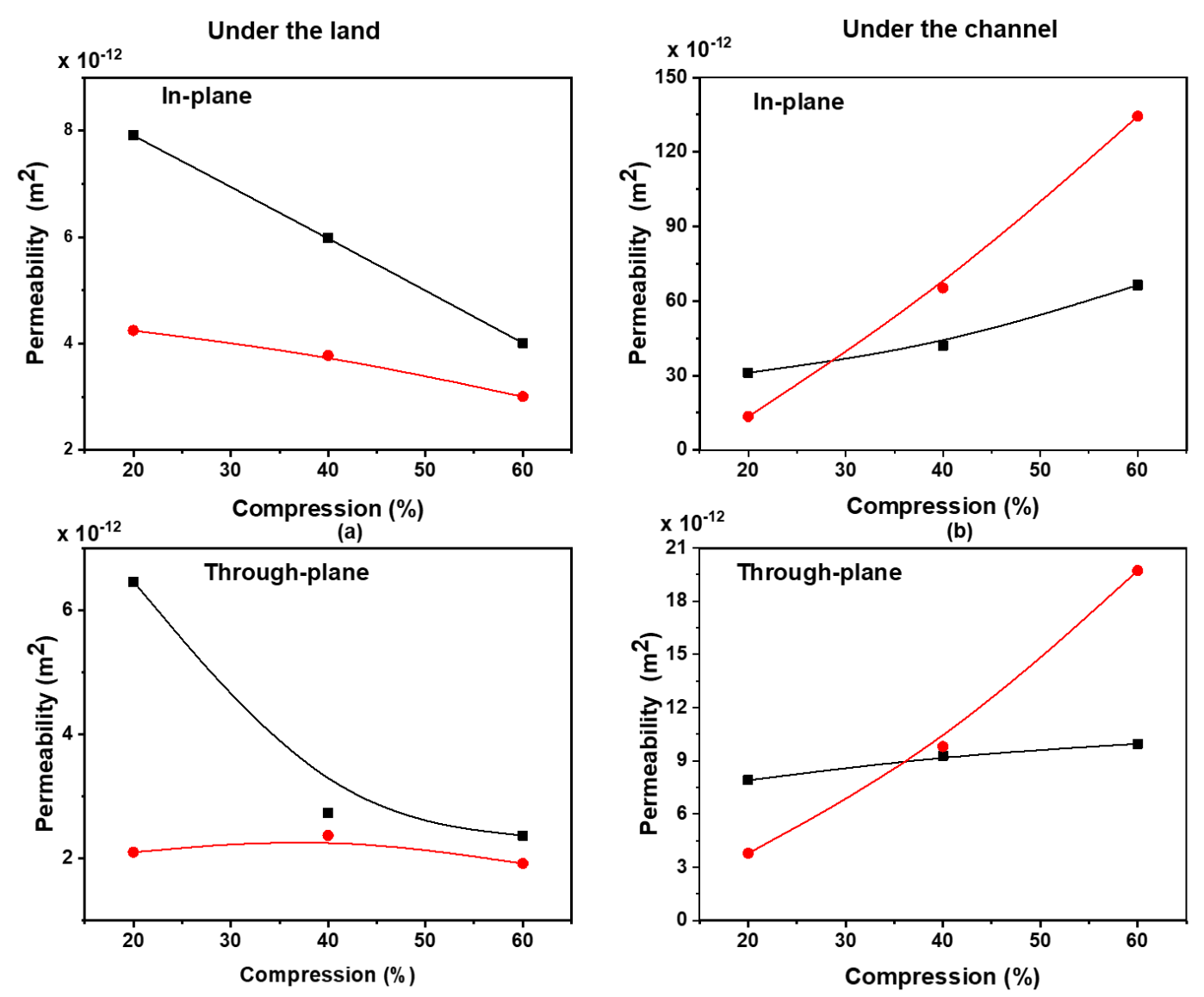

(c)

(d)

Asymmetrical flow-field - - Symmetrical flow-field

Figure 8 Change in directional permeability with compression and flow-fields: (a) in-plane permeability under the land; (b) inplane permeability under the channel; (c) through-plane permeability under the land; and (d) through-plane permeability under the channel. The B-spline passing through the data points is added as a guide to the eye.

\section{Conclusions}

Lab-based X-ray CT was used to study the geometrical and morphological heterogeneity of the entire MEA under non-uniform compression. Generated datasets can be used as inputs for the continuum modelling of fuel cell operation, taking the effect of cell compression into account. Also, the results can be used to aid system design and optimisation. The key findings from this study are:

- Non-uniform compression results in partial blocking of the active flow-fields. $25-40 \%$ blocking of the primary flow-field would not only affect the reactant transport capacity of the flow-field but also, it would affect the cell cooling characteristics. This emphasises the importance of considering compression ratio while designing and modelling flow-fields and their arrangements. The results presented in this study can be used for design guidance. 
- The electrolyte membrane undergoes deflection due to non-uniform compression and the extent of membrane deflection is dependent on the arrangement. The lateral shift of the piston at the extreme symmetrical compression results in delamination of the MEA. This highlights the importance of channel alignment during cell assembly and manufacturing tolerances.

- This study presents the heterogeneity in the membrane that occurs from the MEA fabrication and hot pressing and considers the structure thinning of the membrane under the land, due to non-uniform compression. This would affect the membrane durability, gas-crossover rates and subsequent water management.

- Cell compression and arrangements affect the extent of interfacial contact area and quality of the contact, which defines the contact resistance. GDL tenting increases the contact area through carbon fibres touching the flow-channel surface. The increase in contact area with compression would lower the contact resistance at the cost of flowfield blocking. This emphasises the nonlinear relationship between contact resistance and cell performance.

- The X-ray CT data presented in this study prove that the bulk porosity values used in the modelling are valid only in the in-plane direction and does not represent the through-plane behaviour. Through-plane behaviour is critical in predicting water transport in the porous medium.

- Spatially resolved tortuosity, diffusivity, and permeability follow well-defined trends, such as the reduction in the porosity under the land area, resulting in an increase in tortuosity, and a reduction in diffusivity and permeability. The values obtained from the study can be used as the input parameters in continuum modelling.

Thus, the present work provides a comprehensive dataset of the structural and morphological properties of the MEA, as well as effective parameters that can be used as inputs to higher fidelity computational models predicting PEMFC performance, and provides detailed insight into the structural behaviour of the membrane under compression.

\section{Acknowledgements}

The authors would like to acknowledge funding from the EPSRC (EP/L015277/1, EP/P009050/1, EP/M014371/1, EP/M009394/1, EP/M023508/1, EP/L015749/1, EP/N022971/1) for supporting fuel cell research in the Electrochemical Innovation Lab (EIL) 
and to the Digital Engineering and Test Centre (APC Spoke) Virtually Connected Hybrid Vehicle (VCHV) project for supporting N. Kulkarni.

\section{References}

[1] J.S. Cooper, Design analysis of PEMFC bipolar plates considering stack manufacturing and environment impact, J. Power Sources. 129 (2004) 152-169. doi:10.1016/j.jpowsour.2003.11.037.

[2] D. Candusso, F. Harel, A. De Bernardinis, X. Francois, M. Pera, D. Hissel, P. Schott, G. Coquery, J. Kauffmann, Characterisation and modelling of a 5kW PEMFC for transportation applications, Int. J. Hydrogen Energy. 31 (2006) 1019-1030. doi:10.1016/j.ijhydene.2005.11.010.

[3] R.K. Ahluwalia, X. Wang, Fuel cell systems for transportation: Status and trends, J. Power Sources. 177 (2008) 167-176. doi:10.1016/j.jpowsour.2007.10.026.

[4] R. Anderson, L. Zhang, Y. Ding, M. Blanco, X. Bi, D.P. Wilkinson, A critical review of two-phase flow in gas flow channels of proton exchange membrane fuel cells, J. Power Sources. 195 (2010) 4531-4553. doi:10.1016/j.jpowsour.2009.12.123.

[5] F. Barbir, PEM Fuel Cells: Theory and Practice, Strateg. Manag. J. 22 (2005) 314. doi:10.1016/B978-012-387710-9.00012-6.

[6] V.B. Oliveira, C.M. Rangel, A.M.F.R. Pinto, Effect of anode and cathode flow field design on the performance of a direct methanol fuel cell, Chem. Eng. J. 157 (2010) 174-180. doi:10.1016/j.cej.2009.11.033.

[7] D.J.L. Brett, N.P. Brandon, Review of Materials and Characterization Methods for Polymer Electrolyte Fuel Cell Flow-Field Plates, J. Fuel Cell Sci. Technol. 4 (2007) 29. doi:10.1115/1.2393303.

[8] Q. Meyer, S. Ashton, S. Torija, C. Gurney, P. Boillat, M. Cochet, E. Engebretsen, D.P. Finegan, P. Adcock, P.R. Shearing, D.J.L. Brett, Nitrogen Blanketing and Hydrogen Starvation in Dead-EndedAnode Polymer Electrolyte Fuel Cells Revealed by Hydro-Electro-Thermal Analysis, Electrochim. Acta. 203 (2016) 198-205. doi:10.1016/j.electacta.2016.04.018.

[9] K. Watanabe, K. Hamada, T. Araki, Visualization technique for time-variant hydrogen concentration distribution in porous materials using hydrogen storage alloy thin film, Int. J. Hydrogen Energy. 43 (2018) 12377-12385. doi:10.1016/j.ijhydene.2018.04.180.

[10] P. Stahl, J. Biesdorf, P. Boillat, J. Kraft, K. a. Friedrich, Water Distribution Analysis in the Outer Perimeter Region of Technical PEFC Based on Neutron Radiography, J. Electrochem. Soc. 162 (2015) F677-F685. doi:10.1149/2.0351507jes.

[11] B. Sompalli, B.A. Litteer, W. Gu, H.A. Gasteiger, Membrane Degradation at Catalyst Layer Edges in PEMFC MEAs, J. Electrochem. Soc. 154 (2007) B1349. doi:10.1149/1.2789791.

[12] T.J. Mason, J. Millichamp, T.P. Neville, A. El-kharouf, B.G. Pollet, D.J.L. Brett, Effect of clamping pressure on ohmic resistance and compression of gas diffusion layers for polymer electrolyte fuel cells, J. Power Sources. 219 (2012) 52-59.

https://www.sciencedirect.com/science/article/pii/S0378775312011469\#fig5 (accessed March 21, 2018).

[13] E. Carcadea, M. Varlam, D.B. Ingham, L.G. Patularu, A. Marinoiu, D. Ion-Ebrasu, I. Stefanescu, Effect of Gdl(+MPL) Compression on the PEM Fuel Cell Performance, Meet. Abstr. MA2016-02 (2016) 2742-2742. http://ma.ecsdl.org/content/MA2016-02/38/2742.

[14] T. Hottinen, O. Himanen, PEMFC temperature distribution caused by inhomogeneous compression of GDL, 2007. doi:10.1016/j.elecom.2006.12.018.

[15] I. Nitta, T. Hottinen, O. Himanen, M. Mikkola, Inhomogeneous compression of PEMFC gas diffusion layer, J. Power Sources. 171 (2007) 26-36. doi:10.1016/j.jpowsour.2006.11.018.

[16] Z. Lu, C. Kim, A.M. Karlsson, J.C. Cross, M.H. Santare, Effect of gas diffusion layer modulus and land-groove geometry on membrane stresses in proton exchange membrane fuel cells, J. Power Sources. 196 (2011) 4646-4654. doi:10.1016/j.jpowsour.2011.01.028.

[17] T. Hottinen, O. Himanen, S. Karvonen, I. Nitta, Inhomogeneous compression of PEMFC gas diffusion layer, J. Power Sources. 171 (2007) 113-121. doi:10.1016/j.jpowsour.2006.10.076.

[18] N. Parikh, J. Allen, R.S. Yassar, Effect of deformation on electrical properties of carbon fibers used in gas diffusion layer of proton exchange membrane fuel cells, J. Power Sources. 193 (2009) 766-768. doi:10.1016/j.jpowsour.2009.04.061.

[19] R.W. Atkinson, Y. Garsany, B.D. Gould, K.E. Swider-Lyons, I. V. Zenyuk, The Role of Compressive Stress on Gas Diffusion Media Morphology and Fuel Cell Performance, ACS Appl. Energy Mater. (2017) acsaem.7b00077. doi:10.1021/acsaem.7b00077. 
[20] I. Nitta, O. Himanen, M. Mikkola, Contact resistance between gas diffusion layer and catalyst layer of PEM fuel cell, 2008. doi:10.1016/j.elecom.2007.10.029.

[21] J. Ge, A. Higier, H. Liu, Effect of gas diffusion layer compression on PEM fuel cell performance, J. Power Sources. 159 (2006) 922-927. doi:10.1016/j.jpowsour.2005.11.069.

[22] I. V. Zenyuk, D.Y. Parkinson, L.G. Connolly, A.Z. Weber, Gas-diffusion-layer structural properties under compression via X-ray tomography, J. Power Sources. 328 (2016) 364-376.

doi:10.1016/j.jpowsour.2016.08.020.

[23] C. Tötzke, I. Manke, T. Arlt, H. Markötter, N. Kardjilov, A. Hilger, S.H. Williams, P. Krüger, R. Kuhn, C. Hartnig, J. Scholta, J. Banhart, Investigation of fuel cells using scanning neutron imaging and a focusing neutron guide, Nucl. Instruments Methods Phys. Res. Sect. A Accel. Spectrometers, Detect. Assoc. Equip. 663 (2012) 48-54. doi:10.1016/j.nima.2011.09.054.

[24] N. Kulkarni, Q. Meyer, J. Hack, R. Jervis, F. Iacoviello, K. Ronaszegi, P. Adcock, P.R. Shearing, D.J.L. Brett, Examining the effect of the secondary flow-field on polymer electrolyte fuel cells using X-ray computed radiography and computational modelling, Int. J. Hydrogen Energy. 44 (2019) 1139-1150. doi:10.1016/j.ijhydene.2018.11.038.

[25] J.P. James, H.-W. Choi, J.G. Pharoah, X-ray computed tomography reconstruction and analysis of polymer electrolyte membrane fuel cell porous transport layers, Int. J. Hydrogen Energy. 37 (2012) 18216-18230. doi:10.1016/j.ijhydene.2012.08.077.

[26] Q. Meyer, S. Ashton, P. Boillat, M. Cochet, E. Engebretsen, D.P. Finegan, X. Lu, J.J. Bailey, N. Mansor, R. Abdulaziz, O.O. Taiwo, R. Jervis, S. Torija, P. Benson, S. Foster, P. Adcock, P.R. Shearing, D.J.L. Brett, Effect of gas diffusion layer properties on water distribution across air-cooled, opencathode polymer electrolyte fuel cells: A combined ex-situ X-ray tomography and in-operando neutron imaging study, Electrochim. Acta. 211 (2016) 478-487. doi:10.1016/j.electacta.2016.06.068.

[27] H. Ostadi, P. Rama, Y. Liu, R. Chen, X.X. Zhang, K. Jiang, 3D reconstruction of a gas diffusion layer and a microporous layer, J. Memb. Sci. 351 (2010) 69-74. doi:10.1016/j.memsci.2010.01.031.

[28] S. Hasanpour, M. Hoorfar, A.B. Phillion, Characterization of transport phenomena in porous transport layers using X-ray microtomography, J. Power Sources. 353 (2017) 221-229.

doi:10.1016/j.jpowsour.2017.03.153.

[29] C. Tötzke, G. Gaiselmann, M. Osenberg, J. Bohner, T. Arlt, H. Markötter, A. Hilger, F. Wieder, A. Kupsch, B.R. Müller, M.P. Hentschel, J. Banhart, V. Schmidt, W. Lehnert, I. Manke, Three-dimensional study of compressed gas diffusion layers using synchrotron X-ray imaging, J. Power Sources. 253 (2014) 123-131. doi:10.1016/j.jpowsour.2013.12.062.

[30] V. Norouzifard, M. Bahrami, Deformation of PEM fuel cell gas diffusion layers under compressive loading: An analytical approach, J. Power Sources. 264 (2014) 92-99. doi:10.1016/j.jpowsour.2014.04.057.

[31] Z. Fishman, A. Bazylak, Heterogeneous Through-Plane Porosity Distributions for Treated PEMFC GDLs. II. Effect of MPL Cracks, J. Electrochem. Soc. 158 (2011) B846. doi:10.1149/1.3594636.

[32] T. Sasabe, P. Deevanhxay, S. Tsushima, S. Hirai, Soft X-ray visualization of the liquid water transport within the cracks of micro porous layer in PEMFC, Electrochem. Commun. 13 (2011) 638-641. doi:10.1016/j.elecom.2011.03.033.

[33] D. Banham, F. Feng, T. Fürstenhaupt, K. Pei, S. Ye, V. Birss, Novel Mesoporous Carbon Supports for PEMFC Catalysts, Catalysts. 5 (2015) 1046-1067. doi:10.3390/catal5031046.

[34] J. Hack, T.M.M. Heenan, F. Iacoviello, N. Mansor, Q. Meyer, P. Shearing, N. Brandon, D.J.L. Brett, A Structure and Durability Comparison of Membrane Electrode Assembly Fabrication Methods: SelfAssembled Versus Hot-Pressed, J. Electrochem. Soc. 165 (2018) F3045-F3052. doi:10.1149/2.0051806jes.

[35] H. Markötter, I. Manke, P. Krüger, T. Arlt, J. Haussmann, M. Klages, H. Riesemeier, C. Hartnig, J. Scholta, J. Banhart, Investigation of 3D water transport paths in gas diffusion layers by combined in-situ synchrotron X-ray radiography and tomography, Electrochem. Commun. 13 (2011) 1001-1004. doi:10.1016/j.elecom.2011.06.023.

[36] P. Trogadas, O.O. Taiwo, B. Tjaden, T.P. Neville, S. Yun, J. Parrondo, V. Ramani, M. Coppens, D.J.L. Brett, P.R. Shearing, X-ray micro-tomography as a diagnostic tool for the electrode degradation in vanadium redox flow batteries, Electrochem. Commun. 48 (2014) 155-159. doi:10.1016/j.elecom.2014.09.010.

[37] N. Ge, S. Chevalier, J. Lee, R. Yip, R. Banerjee, M.G. George, H. Liu, C. Lee, M. Fazeli, P. Antonacci, T. Kotaka, Y. Tabuchi, A. Bazylak, Non-isothermal two-phase transport in a polymer electrolyte membrane fuel cell with crack-free microporous layers, Int. J. Heat Mass Transf. 107 (2017) 418-431. doi:10.1016/j.ijheatmasstransfer.2016.11.045. 
[38] S. Odaya, R.K. Phillips, Y. Sharma, J. Bellerive, A.B. Phillion, M. Hoorfar, X-ray Tomographic Analysis of Porosity Distributions in Gas Diffusion Layers of Proton Exchange Membrane Fuel Cells, Electrochim. Acta. 152 (2015) 464-472. doi:10.1016/j.electacta.2014.11.143.

[39] R. Kamal, S.H. Chan, Sensitivity analysis of anode overpotential during start-up process of a high temperature proton exchange membrane fuel cell, Electrochim. Acta. 176 (2015) 965-975. doi:10.1016/j.electacta.2015.07.090.

[40] T. Koido, T. Furusawa, K. Moriyama, An approach to modeling two-phase transport in the gas diffusion layer of a proton exchange membrane fuel cell, J. Power Sources. 175 (2008) 127-136. doi:10.1016/j.jpowsour.2007.09.029.

[41] P.A. García-Salaberri, M. Vera, R. Zaera, Nonlinear orthotropic model of the inhomogeneous assembly compression of PEM fuel cell gas diffusion layers, Int. J. Hydrogen Energy. 36 (2011) 11856-11870. doi:10.1016/j.ijhydene.2011.05.152.

[42] R. Lin, Y.S. Ren, X.W. Lin, Z.H. Jiang, Z. Yang, Y.T. Chang, Investigation of the internal behavior in segmented PEMFCs of different flow fields during cold start process, Energy. 123 (2017) 367-377. doi:10.1016/j.energy.2017.01.138.

[43] A.H. Mahmoudi, A. Ramiar, Q. Esmaili, Effect of inhomogeneous compression of gas diffusion layer on the performance of PEMFC with interdigitated flow field, Energy Convers. Manag. 110 (2016) 78 89. doi:10.1016/j.enconman.2015.12.012.

[44] L. Holzer, O. Pecho, J. Schumacher, P. Marmet, O. Stenzel, F.N. Büchi, A. Lamibrac, B. Münch, Microstructure-property relationships in a gas diffusion layer (GDL) for Polymer Electrolyte Fuel Cells, Part I: effect of compression and anisotropy of dry GDL, Electrochim. Acta. 227 (2017) 419-434. doi:10.1016/j.electacta.2017.01.030.

[45] Q. Meyer, S. Ashton, R. Jervis, D.P. Finegan, P. Boillat, M. Cochet, O. Curnick, T. Reisch, P. Adcock, P.R. Shearing, D.J.L. Brett, The hydro-electro-thermal performance of air-cooled, open-cathode polymer electrolyte fuel cells: Combined localised current density, temperature and water mapping, Electrochim. Acta. 180 (2015) 307-315. doi:10.1016/j.electacta.2015.08.106.

[46] Q. Meyer, S. Ashton, O. Curnick, T. Reisch, P. Adcock, K. Ronaszegi, J.B. Robinson, D.J.L. Brett, Dead-ended anode polymer electrolyte fuel cell stack operation investigated using electrochemical impedance spectroscopy, off-gas analysis and thermal imaging, J. Power Sources. 254 (2014) 1-9. doi:10.1016/j.jpowsour.2013.11.125.

[47] C.M. Baca, R. Travis, M. Bang, Three-dimensional, single-phase, non-isothermal CFD model of a PEM fuel cell, J. Power Sources. 178 (2008) 269-281. doi:10.1016/j.jpowsour.2007.12.023.

[48] W. Sun, B.A. Peppley, K. Karan, An improved two-dimensional agglomerate cathode model to study the influence of catalyst layer structural parameters, Electrochim. Acta. 50 (2005) 3359-3374. doi:10.1016/j.electacta.2004.12.009.

[49] R. Satija, D.L. Jacobson, M. Arif, S.A. Werner, In situ neutron imaging technique for evaluation of water management systems in operating PEM fuel cells, J. Power Sources. 129 (2004) 238-245. doi:10.1016/j.jpowsour.2003.11.068.

[50] Q. Meyer, K. Ronaszegi, J.B. Robinson, M. Noorkami, O. Curnick, S. Ashton, A. Danelyan, T. Reisch, P. Adcock, R. Kraume, P.R. Shearing, D.J.L. Brett, Combined current and temperature mapping in an air-cooled, open-cathode polymer electrolyte fuel cell under steady-state and dynamic conditions, J. Power Sources. 297 (2015) 315-322. doi:10.1016/j.jpowsour.2015.07.069.

[51] Q. Meyer, N. Mansor, F. Iacoviello, P.L. Cullen, R. Jervis, D. Finegan, C. Tan, J. Bailey, P.R. Shearing, D.J.L. Brett, Investigation of Hot Pressed Polymer Electrolyte Fuel Cell Assemblies via X-ray Computed Tomography, Electrochim. Acta. 242 (2017) 125-136. doi:10.1016/j.electacta.2017.05.028.

[52] M. Göbel, M. Godehardt, K. Schladitz, Multi-scale structural analysis of gas diffusion layers, J. Power Sources. 355 (2017) 8-17. doi:10.1016/j.jpowsour.2017.03.086.

[53] J. Ma, X. Zhang, Z. Jiang, H. Ostadi, K. Jiang, R. Chen, Flow properties of an intact MPL from nanotomography and pore network modelling, Fuel. 136 (2014) 307-315. doi:10.1016/j.fuel.2014.07.040.

[54] H. Ostadi, P. Rama, Y. Liu, R. Chen, X.X. Zhang, K. Jiang, Influence of threshold variation on determining the properties of a polymer electrolyte fuel cell gas diffusion layer in X-ray nanotomography, Chem. Eng. Sci. 65 (2010) 2213-2217. doi:10.1016/j.ces.2009.12.019.

[55] P.A. García-Salaberri, I. V. Zenyuk, A.D. Shum, G. Hwang, M. Vera, A.Z. Weber, J.T. Gostick, Analysis of representative elementary volume and through-plane regional characteristics of carbon-fiber papers: diffusivity, permeability and electrical/thermal conductivity, Int. J. Heat Mass Transf. 127 (2018) 687-703. doi:10.1016/j.ijheatmasstransfer.2018.07.030.

[56] C. Tötzke, G. Gaiselmann, M. Osenberg, T. Arlt, H. Markötter, A. Hilger, A. Kupsch, B.R. Müller, V. Schmidt, W. Lehnert, I. Manke, Influence of hydrophobic treatment on the structure of compressed gas 
diffusion layers, J. Power Sources. 324 (2016) 625-636. doi:10.1016/j.jpowsour.2016.05.118.

[57] R. Banerjee, J. Hinebaugh, H. Liu, R. Yip, N. Ge, A. Bazylak, Heterogeneous porosity distributions of polymer electrolyte membrane fuel cell gas diffusion layer materials with rib-channel compression, Int. J. Hydrogen Energy. 41 (2016) 14885-14896. doi:10.1016/j.ijhydene.2016.06.147.

[58] Z. Fishman, J. Hinebaugh, A. Bazylak, Microscale Tomography Investigations of Heterogeneous Porosity Distributions of PEMFC GDLs, J. Electrochem. Soc. 157 (2010) B1643. doi:10.1149/1.3481443.

[59] N. Khajeh-Hosseini-Dalasm, T. Sasabe, T. Tokumasu, U. Pasaogullari, Effects of polytetrafluoroethylene treatment and compression on gas diffusion layer microstructure using highresolution X-ray computed tomography, J. Power Sources. 266 (2014) 213-221. doi:10.1016/j.jpowsour.2014.05.004.

[60] J.G. Pharoah, K. Karan, W. Sun, On effective transport coefficients in PEM fuel cell electrodes: Anisotropy of the porous transport layers, J. Power Sources. 161 (2006) 214-224. doi:10.1016/j.jpowsour.2006.03.093.

[61] R. Flückiger, S.A. Freunberger, D. Kramer, A. Wokaun, G.G. Scherer, F.N. Büchi, Anisotropic, effective diffusivity of porous gas diffusion layer materials for PEFC, Electrochim. Acta. 54 (2008) 551-559. doi:10.1016/j.electacta.2008.07.034.

[62] A. Kusoglu, A.M. Karlsson, M.H. Santare, S. Cleghorn, W.B. Johnson, Mechanical response of fuel cell membranes subjected to a hygro-thermal cycle, J. Power Sources. 161 (2006) 987-996. doi:10.1016/j.jpowsour.2006.05.020.

[63] Y. Tang, M.H. Santare, A.M. Karlsson, S. Cleghorn, W.B. Johnson, Stresses in Proton Exchange Membranes Due to Hygro-Thermal Loading, J. Fuel Cell Sci. Technol. 3 (2006) 119. doi:10.1115/1.2173666.

[64] A. Therdthianwong, P. Manomayidthikarn, S. Therdthianwong, Investigation of membrane electrode assembly (MEA) hot-pressing parameters for proton exchange membrane fuel cell, Energy. 32 (2007) 2401-2411. doi:10.1016/J.ENERGY.2007.07.005.

[65] M.D.R. Kok, R. Jervis, T.G. Tranter, M.A. Sadeghi, D.J.L. Brett, P.R. Shearing, J.T. Gostick, Mass transfer in fibrous media with varying anisotropy for flow battery electrodes: Direct numerical simulations with 3D X-ray computed tomography, Chem. Eng. Sci. (2018). doi:10.1016/J.CES.2018.10.049.

[66] K.D. Baik, M.S. Kim, Characterization of nitrogen gas crossover through the membrane in protonexchange membrane fuel cells, Int. J. Hydrogen Energy. 36 (2011) 732-739.

doi:10.1016/j.ijhydene.2010.09.046.

[67] P. Zhou, C.W. Wu, G.J. Ma, Contact resistance prediction and structure optimization of bipolar plates, J. Power Sources. 159 (2006) 1115-1122. doi:10.1016/j.jpowsour.2005.12.080.

[68] P. Zhou, C.W. Wu, G.J. Ma, Influence of clamping force on the performance of PEMFCs, J. Power Sources. 163 (2007) 874-881. doi:10.1016/j.jpowsour.2006.09.068.

[69] H. Sadeghifar, In-plane and through-plane electrical conductivities and contact resistances of a Mercedes-Benz catalyst-coated membrane, gas diffusion and micro-porous layers and a Ballard graphite bipolar plate: Impact of humidity, compressive load and polytetrafluoroethylene, Energy Convers. Manag. 154 (2017) 191-202. doi:10.1016/j.enconman.2017.10.060.

[70] J. Ihonen, F. Jaouen, G. Lindbergh, G. Sundholm, A novel polymer electrolyte fuel cell for laboratory investigations and in-situ contact resistance measurements, Electrochim. Acta. 46 (2001) 2899-2911. doi:10.1016/S0013-4686(01)00510-2.

[71] Y. Zhou, G. Lin, A.J. Shih, S.J. Hu, A micro-scale model for predicting contact resistance between bipolar plate and gas diffusion layer in PEM fuel cells, 163 (2007) 777-783. doi:10.1016/j.jpowsour.2006.09.019.

[72] S.J. Cooper, A. Bertei, P.R. Shearing, J.A. Kilner, N.P. Brandon, TauFactor: An open-source application for calculating tortuosity factors from tomographic data, SoftwareX. 5 (2016) 203-210. doi:10.1016/j.softx.2016.09.002.

[73] L. Hao, P. Cheng, Lattice Boltzmann simulations of anisotropic permeabilities in carbon paper gas diffusion layers, J. Power Sources. 186 (2009) 104-114. doi:10.1016/j.jpowsour.2008.09.086.

[74] D. Froning, J. Brinkmann, U. Reimer, V. Schmidt, W. Lehnert, D. Stolten, 3D analysis, modeling and simulation of transport processes in compressed fibrous microstructures, using the Lattice Boltzmann method, Electrochim. Acta. 110 (2013) 325-334. doi:10.1016/j.electacta.2013.04.071.

[75] A. Nabovati, J. Hinebaugh, A. Bazylak, C.H. Amon, Effect of porosity heterogeneity on the permeability and tortuosity of gas diffusion layers in polymer electrolyte membrane fuel cells, J. Power Sources. 248 (2014) 83-90. doi:10.1016/j.jpowsour.2013.09.061. 
[76] J.T. Gostick, M.W. Fowler, M.D. Pritzker, M.A. Ioannidis, L.M. Behra, In-plane and through-plane gas permeability of carbon fiber electrode backing layers, J. Power Sources. 162 (2006) 228-238. doi:10.1016/j.jpowsour.2006.06.096.

[77] M.D.R. Kok, R. Jervis, D. Brett, P.R. Shearing, J.T. Gostick, Insights into the Effect of Structural Heterogeneity in Carbonized Electrospun Fibrous Mats for Flow Battery Electrodes by X-Ray Tomography, Small. 14 (2018) 1-15. doi:10.1002/smll.201703616.

[78] M. Januszewski, M. Kostur, Sailfish: A flexible multi-GPU implementation of the lattice Boltzmann method, Comput. Phys. Commun. 185 (2014) 2350-2368. doi:10.1016/j.cpc.2014.04.018. 